\title{
Supervillin slows cell spreading by facilitating myosin II activation at the cell periphery
}

\author{
Norio Takizawa ${ }^{1,3, \star}$, Reiko Ikebe ${ }^{2,3}$, Mitsuo Ikebe $^{2,3}$ and Elizabeth J. Luna ${ }^{1,3}$ \\ ${ }^{1}$ Department of Cell Biology, ${ }^{2}$ Department of Physiology and ${ }^{3}$ Cell Dynamics Program, University of Massachusetts Medical School, Worcester, MA \\ 01605, USA \\ *Author for correspondence (e-mail: Norio.Takizawa@umassmed.edu)
}

Accepted 6 August 2007

Journal of Cell Science 120, 3792-3803 Published by The Company of Biologists 2007 doi:10.1242/jcs.008219

\section{Summary}

During cell migration, myosin II modulates adhesion, cell protrusion and actin organization at the leading edge. We show that an F-actin- and membrane-associated scaffolding protein, called supervillin (SV, p205), binds directly to the subfragment 2 domains of nonmuscle myosin IIA and myosin IIB and to the N-terminus of the long form of myosin light chain kinase (L-MLCK). SV inhibits cell spreading via an MLCK- and myosin II-dependent mechanism. Overexpression of SV reduces the rate of cell spreading, and RNAi-mediated knockdown of endogenous SV increases it. Endogenous and EGFP-tagged SV colocalize with, and enhance the formation of, cortical bundles of F-actin and activated myosin II during early cell spreading. The effects of SV are reversed by inhibition of myosin heavy chain (MHC) ATPase (blebbistatin), MLCK (ML-7) or MEK (U0126), but not by inhibiting Rho-kinase with Y-27632. Flag-tagged L-MLCK co-localizes in cortical bundles with EGFP-SV, and kinase-dead L-MLCK disorganizes these bundles. The L-MLCK- and myosinbinding site in SV, SV1-171, rearranges and co-localizes with mono- and di-phosphorylated myosin light chain and with L-MLCK, but not with the short form of MLCK (SMLCK) or with myosin phosphatase. Thus, the membrane protein SV apparently contributes to myosin II assembly during cell spreading by modulating myosin II regulation by L-MLCK.

Supplementary material available online at http://jcs.biologists.org/cgi/content/full/120/21/3792/DC1

Key words: Supervillin, Myosin II, MLCK, Cell spreading, Cytoskeleton

\section{Introduction}

Cell migration is a multi-step process involving surface protrusion, substrate attachment at integrin- and actomyosinassociated focal adhesions, myosin II-based retraction of the cell body, and substrate detachment (Bretscher, 1996; Lauffenburger and Horwitz, 1996; Lin and Forscher, 1995). Cell spreading, the initial step in this process, can be modeled by plating cells onto fibronectin-coated coverslips (Betapudi et al., 2006; Cai et al., 2006; Duxbury et al., 2004; Wakatsuki et al., 2003) and can be approximated as the sum of two forces (Wylie and Chantler, 2003). The outward force, driven by actin polymerization, is opposed by a myosin II-driven inward contractile force associated with F-actin bundling and remodeling in a transitional zone behind the extending cell surface (Brown and Bridgman, 2003; Cai et al., 2006; Gupton and Waterman-Storer, 2006; Medeiros et al., 2006; Wakatsuki et al., 2003).

Recent work with cells deficient in individual myosin II isoforms implicates myosin IIB as being primarily responsible for focal adhesion stabilization during rapid cell surface extension, whereas myosin IIA is implicated in the contractile forces that reduce the rate of cell spreading (Betapudi et al., 2006; Bridgman et al., 2001; Cai et al., 2006; Lo et al., 2004; Vincente-Manzanares, 2007; Wylie and Chantler, 2003). This generalization is tempered by cell type-specific differences both in myosin II isoforms and in myosin II-binding regulatory proteins (Bao et al., 2005; Betapudi et al., 2006; Cai et al., 2006; Simerly et al., 1998; Togo and Steinhardt, 2004). The

fact that some cells contain only one nonmuscle myosin isoform [e.g. COS7 cells contain only myosin IIB (Betapudi et al., 2006)] indicates a large degree of functional redundancy among myosin II isoforms.

Myosin II activation is regulated by monophosphorylation of its regulatory $20 \mathrm{kDa}$ light chain (myosin light chain, MLC) on serine-19 and diphosphorylation at a second residue, threonine-18 (Ikebe, 1989). Diphosphorylation also differentially stabilizes the extended, filamentous conformation of myosin (Ikebe et al., 1988; Matsumura, 2005; Watanabe et al., 2007). Many kinases can phosphorylate and activate MLC, with Rho kinase and MLC kinase (MLCK) among the chief regulators (Matsumura, 2005; Murthy, 2006). These enzymes mediate both mono- and di-phosphorylation of MLC (Choi et al., 1994; Ikebe, 1989; Itoh et al., 1992; Ueda et al., 2002). Rho kinase regulates MLC phosphorylation in the cell interior (Totsukawa et al., 2004) and controls the development of traction forces in adhesive fibroblasts (Beningo et al., 2006), perhaps via selective modulation of myosin IIB (Sandquist et al., 2006), but is not a major contributor during cell spreading (Betapudi et al., 2006; Totsukawa et al., 2004). MLCK promotes MLC phosphorylation in the cell periphery and along stress fibers (Chew et al., 2002; Totsukawa et al., 2004). MLCK also preferentially co-localizes with myosin IIA (Blue et al., 2002) and regulates integrin-dependent cell survival (Connell and Helfman, 2006; Fazal et al., 2005), perhaps via a signaling cascade downstream of Ras and MEK (Nguyen et al., 1999). This model is consistent with the 
requirement for the kinase activities of MLCK and extracellular signal-regulated kinase (ERK, also called MAPK), both of which are downstream of MEK during focal adhesion disassembly (Webb et al., 2004).

Negative regulation of MLC phosphorylation in nonmuscle cells is mostly mediated by a tripartite myosin phosphatase comprised of a $\sim 130 \mathrm{kDa}$ targeting subunit called MYPT1, a $\sim 38 \mathrm{kDa}$ catalytic subunit and a $\sim 20 \mathrm{kDa}$ subunit (reviewed in Matsumura, 2005; Murthy, 2006). MYPT1 binds to the myosin S2 subfragment, bringing the catalytic phosphatase into proximity with MLC (Johnson et al., 1997). Several of the kinases that promote MLC activation simultaneously phosphorylate and downregulate myosin phosphatase activity (Ito et al., 2004; Matsumura, 2005).

We have identified a plasma membrane-associated cytoskeletal fraction that contains myosin II, F-actin and signaling proteins in association with a tightly bound peripheral membrane protein called supervillin (SV, p205) (Nebl et al., 2002; Pestonjamasp et al., 1997). Over 95\% of SV in differentiated cells localizes and co-fractionates with plasma membranes (Nebl et al., 2002; Oh et al., 2003; Pestonjamasp et al., 1997; Wulfkuhle et al., 1999). SV also co-isolates as part of a cytoskeletal complex with $\beta 2$-integrin, receptor protein tyrosine phosphatase $\beta$ and the $\mathrm{P}_{2} \mathrm{X}_{7}$ ATP-gated ion channel, which regulates cell growth, apoptosis and membrane blebbing (Kim et al., 2001). SV negatively regulates cell-substrate adhesion through interactions with the LIM domains of thyroid receptor-interacting protein 6 (TRIP6) and lipoma-preferred partner (LPP) (Takizawa et al., 2006). Alternatively spliced forms of SV found in striated and smooth muscle are involved in the organization of muscle costameres, stimulus-mediated contractility of smooth muscle and myogenic differentiation (Gangopadhyay et al., 2004; Oh et al., 2003). Thus, SV apparently helps transmit signals across the plasma membrane to the actin- and myosin II-associated cortex.

A role for $\mathrm{SV}$ in regulating membrane-associated cytoskeletal assembly is supported by direct binding to both myosin II and F-actin (Chen et al., 2003). The first 171 amino acids in SV (SV1-171) bind to the S2 regulatory domains of nonmuscle and smooth muscle myosin II heavy chains. SV sequences containing combinations of two of the three F-actinbinding sites within the SV N-terminus (SV amino acids $~ 280$ $342, \sim 344-422$ and $\sim 700-830$ ) also bundle or crosslink actin filaments in vitro (Chen et al., 2003). The TRIP6- and LPPbinding site lies within SV amino acids 342-571 (Takizawa et al., 2006), and the SV C-terminus (SV1542-1792) binds to calponin (Gangopadhyay et al., 2004), which also binds both actin and myosin II and regulates their interaction (ElMezgueldi and Marston, 1996; Lin et al., 1993). Thus, direct or indirect sites of interaction with actin and myosin II are distributed throughout the SV sequence.

We therefore hypothesize that SV is part of a signaling scaffold that organizes and regulates actin and myosin II filaments at the membrane. In addition to mediating focal adhesion turnover via interactions involving TRIP6 in the center of the cell (Takizawa et al., 2006), we hypothesize that $\mathrm{SV}$ modulation of myosin II activity regulates the rate of cell spreading. We show here that SV does modulate cell spreading, apparently by promoting or stabilizing contractile assemblages of actin and myosin II with the long form of MLCK (LMLCK).

\section{Results}

Supervillin inversely regulates cell spreading and associates with peripheral myosin bundles

SV negatively regulates cell spreading on fibronectin (Fig. 1, supplementary material Fig. S1). In populations of COS7 cells spreading onto fibronectin, we noticed that cells expressing EGFP-SV were less well spread than nontransfected cells at 30-45 minutes after plating; no such difference was apparent for cells expressing EGFP only. Initial spreading was essentially complete by 60 minutes for all cells. Defining a 'spread' cell as one exhibiting a radius greater than twice that exhibited by the average initially rounded cell (Fig. 1A, panel a), we quantified the number of spread cells as a function of time after plating (Fig. 1B). COS7 cells expressing an average $\sim 5$-fold excess of EGFP-SV (Takizawa et al., 2006) were

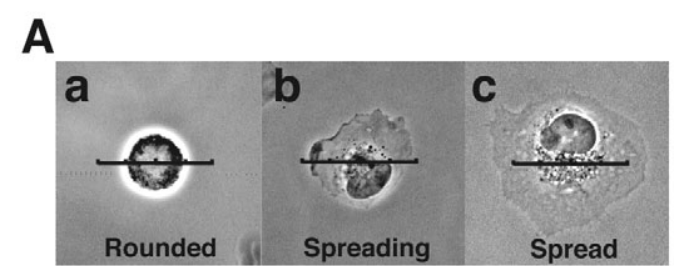

B
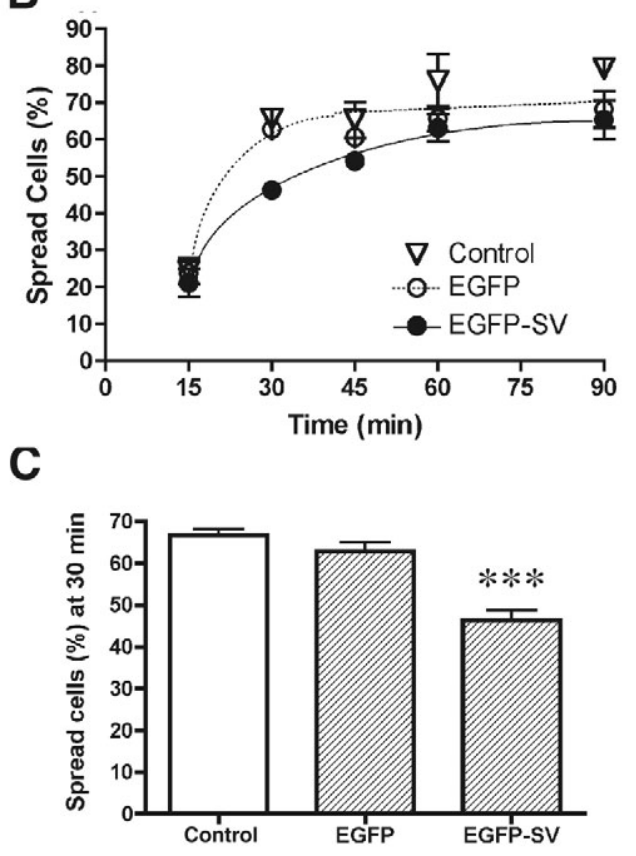

Fig. 1. Overexpressed supervillin decreases the rate of cell spreading. (A) Quantification of spreading and spread cells. As compared with the diameter of rounded cells (a), 'spreading cells' (b) are smaller than twice the diameter of the average rounded COS7 cell, which is 23.0 $\pm 0.7 \mu \mathrm{m}$ (means \pm s.e.m., $n=17$ ), and 'spread cells' (c) are larger than twice the diameter of rounded cells. Bar, $46 \mu \mathrm{m}$. (B) Percentage of spread COS7 cells after plating onto $10 \mu \mathrm{g} / \mathrm{ml}$ fibronectin for 15 , $30,45,60$ or 90 minutes. Results for control nontransfected cells or cells expressing EGFP alone or EGFP-SV were obtained.

Means \pm s.e.m. of 100 cells counted per experiment, $n=6$. Sample images are shown in supplementary material Fig. S1. (C) Histogram of the percentages of spread COS7 cells at 30 minutes after plating on $10 \mu \mathrm{g} / \mathrm{ml}$ fibronectin. Means \pm s.e.m.; $n=6$; $* * * P<0.001$ for EGFP$\mathrm{SV}$ versus both control and EGFP-expressing cells. 
significantly less likely to be spread at 30 minutes, as compared with control cells or cells expressing EGFP alone (Fig. 1C). This result was reminiscent of our previous observations of SVmediated inhibition of cell-substrate adhesion (Takizawa et al., 2006).

During early cell spreading, EGFP-SV and myosin heavy chain (MHC) IIB prominently co-localized in bundles at the cell periphery, in addition to their abundant signals in the cell interior (Fig. 2A, panels a-c). EGFP by itself did not colocalize with myosin bundles after 30 minutes of spreading (Fig. 2A, panels d-f). Indeed, the circumferential myosin bundles were far less prominent in untransfected cells (not shown) or cells expressing only EGFP at this time than in cells with EGFP-SV (Fig. 2A, panel e versus panel b). By 60 minutes of spreading, peripheral and interior bundles of myosin were observed in all three types of cells (Fig. 2B and not shown).

Peripheral bundles of F-actin, activated myosin II and endogenous SV also formed during spreading of A549 human lung carcinoma cells (Fig. 3). These cells spread onto fibronectin with a time course similar to that of COS7 cells (see below). Consistent with previous reports (Cai et al., 2006; LoRusso et al., 1997; Sumoza-Toledo et al., 2006), we found that both MHC IIA and MHC IIB isoforms localize with F-

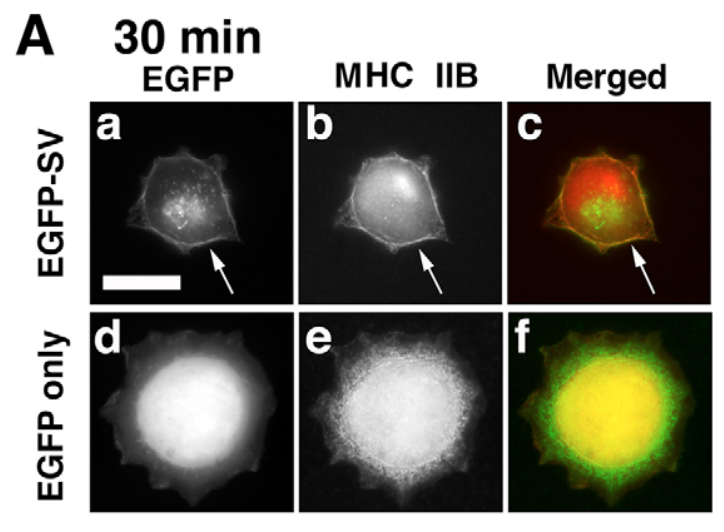

\section{B $60 \mathrm{~min}$}

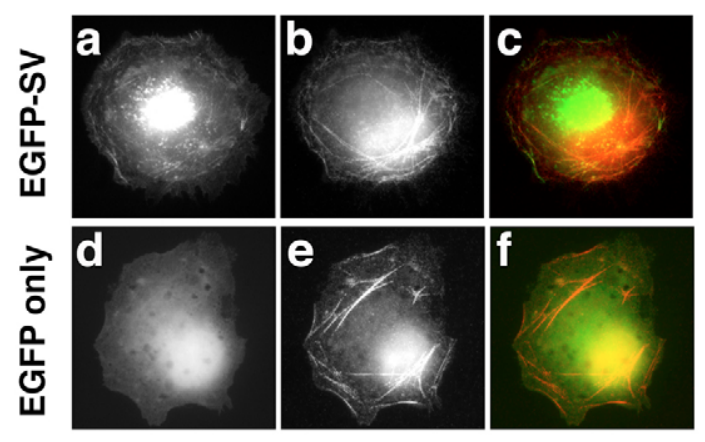

Fig. 2. EGFP-supervillin (EGFP-SV) and myosin heavy chain (MHC) IIB co-localize at the cell periphery during spreading. (A,B) COS7 cells expressing EGFP-SV (upper panels) or EGFP only (lower panels) after 30 (A) or 60 (B) minutes of spreading were counterstained with anti-MHC IIB antibodies. EGFP signals (a,d; green in c,f) and MHC IIB signals visualized in the red channel (b,e; red in c,f) were merged (c,f); signal overlaps are shown in yellow. Arrows indicate peripheral co-localizations. Bar, $20 \mu \mathrm{m}$.

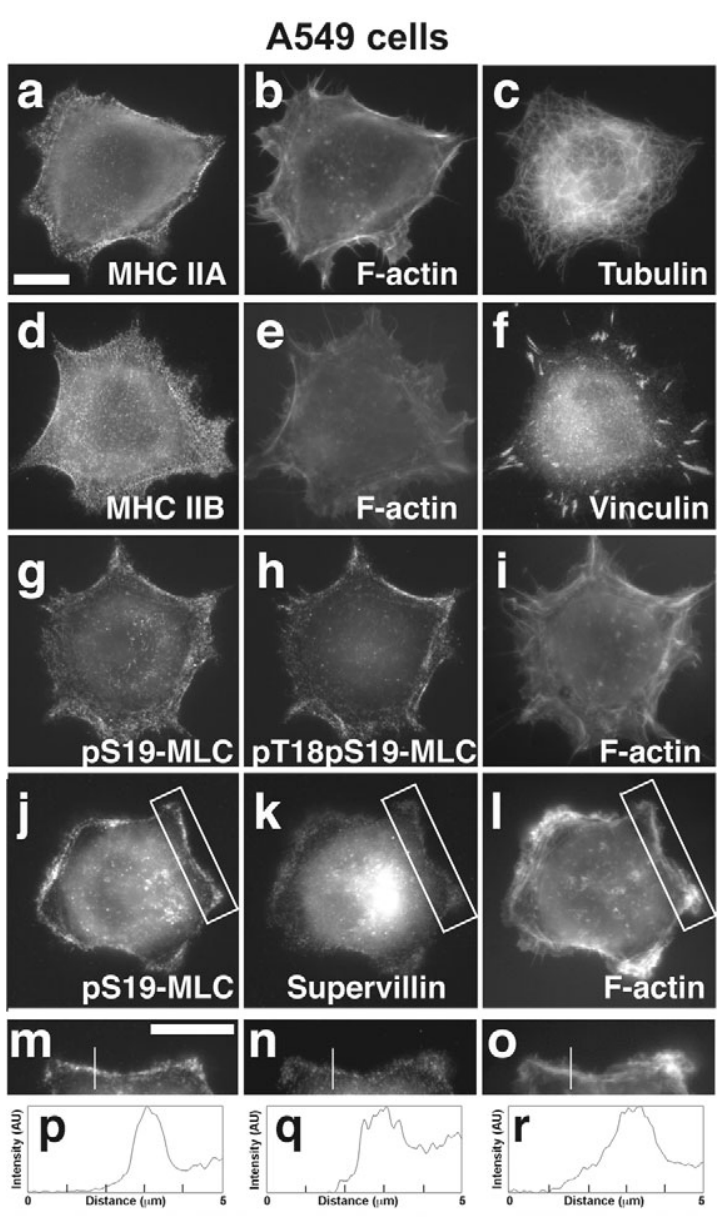

Fig. 3. Co-localization of endogenous proteins during cell spreading. After 30 minutes of spreading on $10 \mu \mathrm{g} / \mathrm{ml}$ fibronectin, A549 cells were stained with antibodies against MHC IIA (a), tubulin (c), MHC IIB (d), vinculin (f), mono-phosphorylated serine-19 in MLC (pS19MLC; g,j,m), di-phosphorylated threonine-18, serine-19 in MLC (pT18pS19-MLC; h), or supervillin (k,n) and with Alexa-Fluor-350conjugated phalloidin for visualizing F-actin $(b, e, i, l, o)$. Alexa-Fluor488-conjugated (a,d,h,k) and Alexa-Fluor-594-conjugated (c,f,g,j) secondary antibodies were used. (m-o) Enlargements of the boxed areas in j-1. (p-r) Cross-sections of signal intensities along the vertical lines in m-o, respectively. Bars, $10 \mu \mathrm{m}$.

actin in peripheral bundles during cell spreading, although MHC IIA staining was more prominent in A549 cells (Fig. 3af). These bundles were associated with vinculin-stained focal adhesions (Fig. 3f) and with singly and doubly phosphorylated MLC (Fig. 3g,h,j), indicating local myosin activation and the potential for contractility. Immunostained endogenous SV at the cell periphery overlapped with activated myosin II, although fainter overlaps of SV with F-actin in myosindepleted lamellipodia also were seen (Fig. 3j-r). Thus, although it contains at least three binding sites for F-actin and only one for MHC II (Chen et al., 2003), SV might preferentially colocalize with myosin II during cell spreading.

To determine whether SV binds preferentially to nonmuscle MHC IIA versus MHC IIB, we analyzed the binding of $6 \times$ Histagged recombinant $\mathrm{S} 2$ domains from these myosins to columns containing GST-tagged SV amino acids 1-174 (GST- 


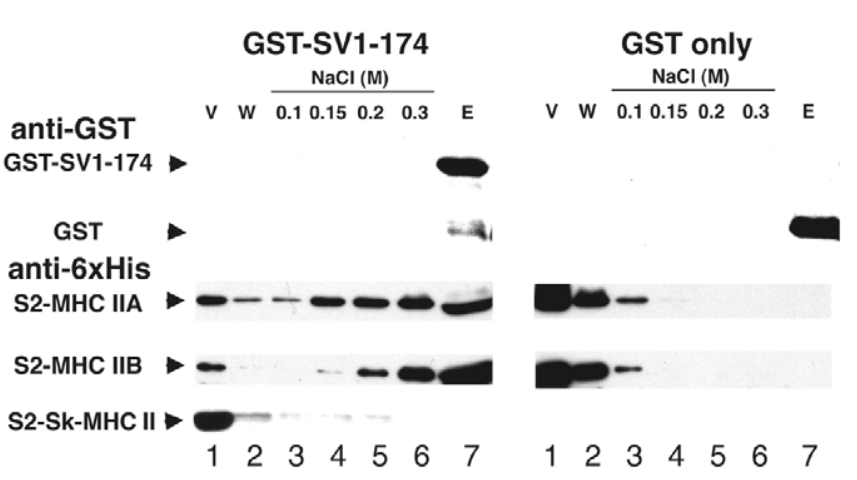

Fig. 4. Supervillin binds to the S2 domains of both of the nonmuscle myosins - myosin IIA and myosin IIB. GST-tagged SV1-174 (left) or GST only (right) were pre-bound to glutathione-agarose beads and incubated with the hexa-histidine $(6 \times$ His $)$-tagged recombinant S2 domain from the heavy chain of nonmuscle myosin IIA (S2-MHC IIA), nonmuscle myosin IIB (S2-MHC II) or skeletal muscle myosin II (S2-Sk-MHC II). Samples (15 $\mu$ l) of void volumes (V, lanes 1), washes with binding buffer (W, lanes 2 ), washes with the indicated concentrations of $\mathrm{NaCl}$ in binding buffer (lanes 3-6) and eluates with $5 \mathrm{mM}$ glutathione (E, lanes 7) were analyzed on immunoblots stained with anti-GST antibodies (top panels) or anti- $6 \times$ His antibodies (lower panels).

SV1-174, Fig. 4). These residues contain the binding site of SV for the smooth muscle myosin S2 domain (Chen et al., 2003). The $S 2$ domains from both nonmuscle myosin isoforms bind to GST-SV1-174 (Fig. 4, left column), but not to GST lacking SV sequences (Fig. 4, right column). Although much less MHC IIB than MHC IIA S2 domain is eluted by physiological levels of salt (Fig. 4, left, lanes 2-4), significant amounts of both myosin isoforms resist extraction with even $0.3 \mathrm{M} \mathrm{NaCl}$, eluting only when GST-SV1-174 is removed from the column (Fig. 4, left, lane 7). As reported previously (Chen et al., 2003), no detectable binding of SV to skeletal muscle myosin II could be observed. Thus, SV can interact with both nonmuscle myosin IIA and nonmuscle myosin IIB isoforms, although associations with myosin IIB might be somewhat stronger.

As expected if endogenous SV plays a role during cell spreading, we found that reduction of SV levels in A549 cells using two different dsRNAs increased the rate of spreading (Fig. 5). Targeting of human SV coding nucleotides 1680-1704 or 2026-2050 with two rounds of dsRNA transfection over 4 days reduced the levels of SV to $\leqslant 10 \%$ of normal amounts without affecting the levels of other proteins analyzed in this study (Fig. 5A). In both live-cell imaging (Fig. 5B; supplementary material Movies 1,2) and counts of spread cells (Fig. 5C), A549 cells with reduced amounts of SV spread faster than either mock-transfected cells or cells treated with a control dsRNA. As with COS7 cells, the largest difference in cell spreading was observed at 30 minutes, when cells treated with either dsRNA against SV were significantly more likely to be spread than cells with normal levels of endogenous protein (Fig. 5D).

During spreading, reduction of endogenous $\mathrm{SV}$ also reduces the extent of peripheral bundles (Fig. 6), defined as arrays of concentrated actin and myosin II at the cell edge or at the base of a lamellipodium (Small et al., 1999). After 30 minutes of
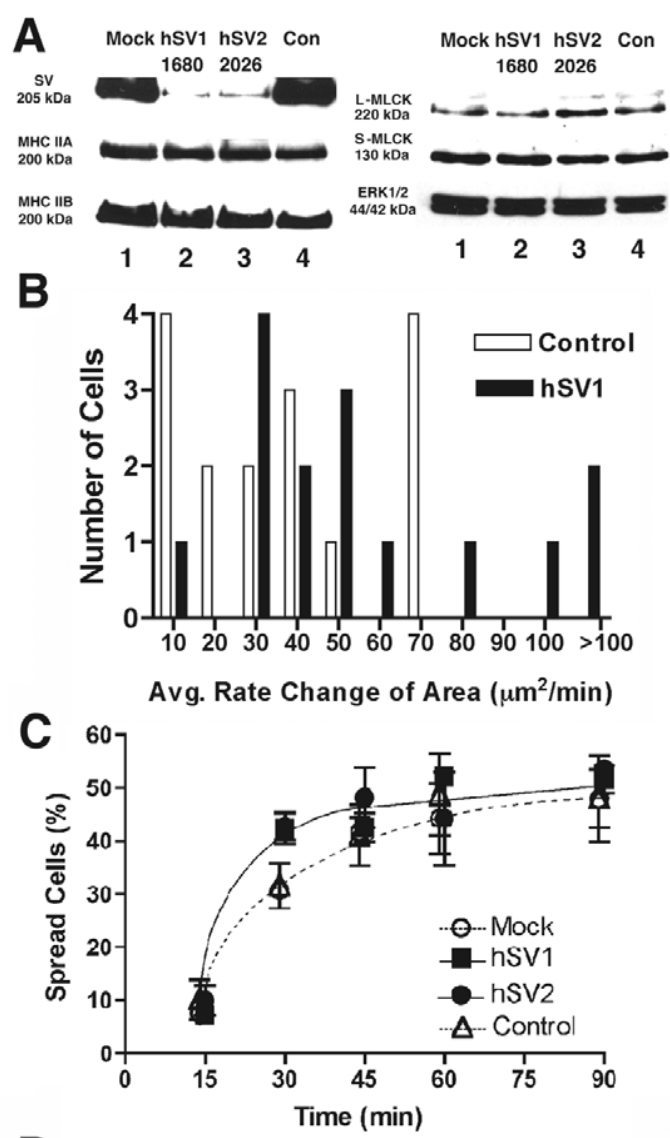

D

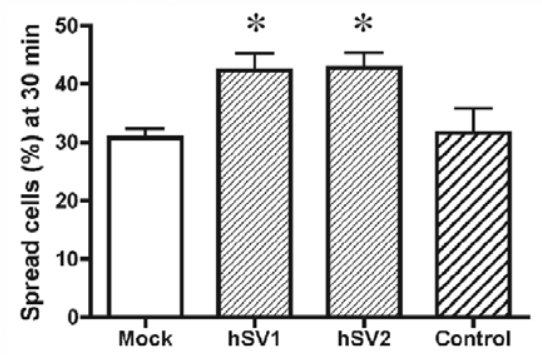

Fig. 5. Supervillin knockdown increases the rate of cell spreading. (A) Immunoblots of endogenous SV, MHC IIA, MHC IIB, long and short isoforms of MLCK (L-MLCK and S-MLCK), and ERK1/2, in lysates from cells treated with transfection reagent alone (lanes 1; Mock), dsRNAs 1680 (hSV1) or 2026 (hSV2) that target SV (lanes 2, 3 ), or control dsRNAs (lanes 4, Con). (B) Histogram showing the rates of area change for populations of A549 cells treated with control (white) or hSV1 (black) dsRNAs spreading on $10 \mu \mathrm{g} / \mathrm{ml}$ fibronectin. Spreading velocities in the bimodal distributions typical of unsynchronized cells (Dubin-Thaler et al., 2004) appear to be displaced, but the difference between the means $\left(36.2 \pm 5.7 \mu \mathrm{m}^{2} /\right.$ minute for controls; $51.7 \pm 11.3$ $\mu \mathrm{m}^{2} /$ minute for hSV1) is not statistically significant for the numbers of living cells $(n=16 ; n=17)$ assayed. Movies 1 and 2 in the supplementary material show cell morphologies during linear spreading for average control- and hSV1-treated cells. (C) Percentage of spread A549 cells after plating onto $10 \mu \mathrm{g} / \mathrm{ml}$ fibronectin at $15,30,45,60$ or 90 minutes. Spread cells were defined as in Fig. 1; the average diameter of a rounded A549 cell was taken as $18.0 \pm 0.8 \mu \mathrm{m}$ (means \pm s.e.m., $n=18$ ). Cells were mock-transfected, or were treated with hSV1, hSV2 or control dsRNA. Means \pm s.e.m. of 200 cells counted per experiment, $n=5$. (D) Percentage of spread A549 cells plated on $10 \mu \mathrm{g} / \mathrm{ml}$ fibronectin for 30 minutes. Means \pm s.e.m.; $n=5$; $* P<0.05$ for each SV dsRNA versus both mock and control dsRNA treatments. 
spreading onto fibronectin, only $\sim 18 \%(n=200)$ of A549 cells treated with a dsRNA against SV contained well-defined peripheral bundles of myosin and actin, whereas $43 \%(n=200)$ of cells treated with a control or no dsRNA contained these structures (Fig. 6A). Activated myosin II filaments were still detectable with antibodies against mono- or doublyphosphorylated MLC, but these structures were more widely distributed throughout the cell cortex (Fig. 6B). Thus, reduced numbers of peripheral bundles of myosin II and F-actin accompany SV-mediated reductions in the rate of cell spreading.

\section{Mediation via MLCK}

To explore the mechanism of SV action during cell spreading, we first treated A549 cells, which contain endogenous SV, with inhibitors of myosin II function (Fig. 7). We found that the rate of cell spreading was increased by blebbistatin, which directly inhibits myosin II ATPase activity (Kovacs et al., 2004; Limouze et al., 2004; Straight et al., 2003); by ML-7 at a concentration $(1 \mu \mathrm{M})$ that specifically inhibits MLCK (Bain et al., 2003); and by the drug U0126, an indirect inhibitor of MLCK via the upstream kinase MEK (Fincham et al., 2000; Nguyen et al., 1999). By contrast, Y-27632, which inhibits direct and indirect activation of myosin by Rho kinase (Amano et al., 1996; Kimura et al., 1996; Uehata et al., 1997), showed no significant effect (Fig. 7).

The formation of circumferential bundles of myosin II and F-actin during spreading of either A549 cells (Fig. 8) or COS7 cells (supplementary material Fig. S2) was inhibited by blebbistatin ( $20 \mu \mathrm{M}$, not shown) or by low concentrations (1 $\mu \mathrm{M})$ of ML-7. As with SV knockdowns, these drugs reduced the percentage of A549 cells with peripheral bundles after 30 minutes of spreading, from $\sim 40 \%$ to $\sim 10 \%(n=200)$. The effect appeared to be selective for peripheral bundles because cytoplasmic myosin II punctae and filaments remained in each cell line treated with $1 \mu \mathrm{M}$ ML-7. Reduced numbers of peripheral bundles of myosin II and F-actin were also observed after indirect inhibition of myosin II activity with U0126 $(2.5 \mu \mathrm{M})$; inhibition of Rho kinase with Y-27632 was without effect (supplementary material Fig. S2). ML-7 and U0126 also virtually eliminated the peripheral localization of phosphorylated MLC (i.e. activated myosin II) (supplementary material Fig. S3). Taken together, these results suggest that MLCK might mediate the effects of SV on the rate of cell spreading and on the formation of peripheral myosin and actin bundles.

The effects of the myosin II inhibitors on SV-mediated changes in cell spreading varied with concentration of blebbistatin and ML-7 (Fig. 9, supplementary material Fig. S4). Low amounts of blebbistatin $(20 \mu \mathrm{M})$ and ML-7 (1 $\mu \mathrm{M})$ abolished SV inhibition of COS7 cell spreading, whereas higher drug concentrations could themselves slow the rate of spreading (Fig. 9A,B), as described previously (Betapudi et al., 2006; Duxbury et al., 2004; Jurado et al., 2005). Slowed spreading at $10 \mu \mathrm{M}$ ML-7 was associated with the disruption of myosin II filaments, of F-actin bundles and of focal adhesions throughout the cell (supplementary material Fig. S4), consistent with the inhibition of all cytoplasmic MLCK and/or inhibition of another myosin II kinase at higher ML-7 concentrations (Komatsu and Ikebe, 2004). By contrast, the inhibitory effects of the MEK inhibitor U0126 (Fig. 9C) and
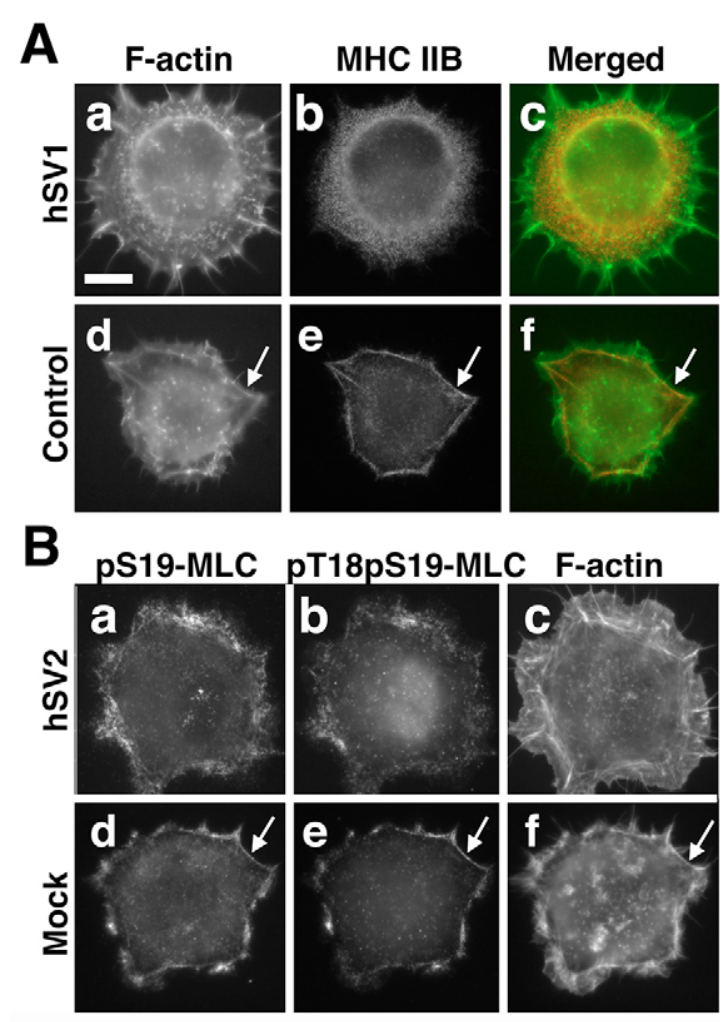

Fig. 6. Supervillin knockdown decreases the number of peripheral bundles of MHC IIB and disorganizes the peripheral localization of phosphorylated MLC. (A) Localization of F-actin (a,d; green in c,f) and MHC IIB (b,e; red in c,f) in A549 cells treated with hSV1 (a-c) or control (d-f) dsRNAs after spreading on fibronectin for 30 minutes. (B) Localization of activated MLC using antibodies against mono-phosphorylated serine-19 (pS19-MLC; a,d), di-phosphorylated threonine-18, serine-19 (pT18pS19-MLC; b,e) and F-actin visualized with Alexa-Fluor-350-phalloidin (c,f). Cells were treated with hSV2 dsRNA (a-c) or were mock-treated (d-f) before spreading on fibronectin for 30 minutes. Signals were visualized in the red (a,d) and green (b,e) channels. Arrows, peripheral bundles. Bars, $10 \mu \mathrm{m}$.

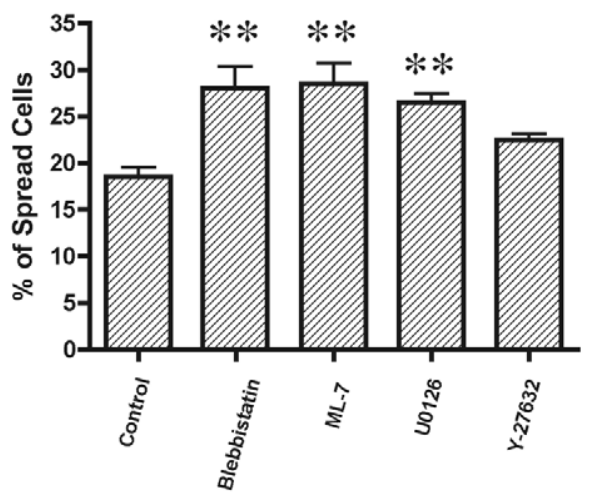

Fig. 7. Inhibition of myosin ATPase activity directly or via MLCK, but not via Rho kinase, increases the rate of A549 cell spreading. Histogram showing the percentage of spread A549 cells plated for 30 minutes on fibronectin in the absence (Control) and presence of specific inhibitors of: myosin II ATPase (blebbistatin, $20 \mu \mathrm{M}$ ), MLCK (ML-7, $1 \mu \mathrm{M})$, the MLCK activator MEK (U0126, $2.5 \mu \mathrm{M})$ or Rho kinase (Y-27632, $20 \mu \mathrm{M}$ ). Means \pm s.e.m.; 200 cells/experiment, $n=6 ; * * P<0.01$ versus control. 


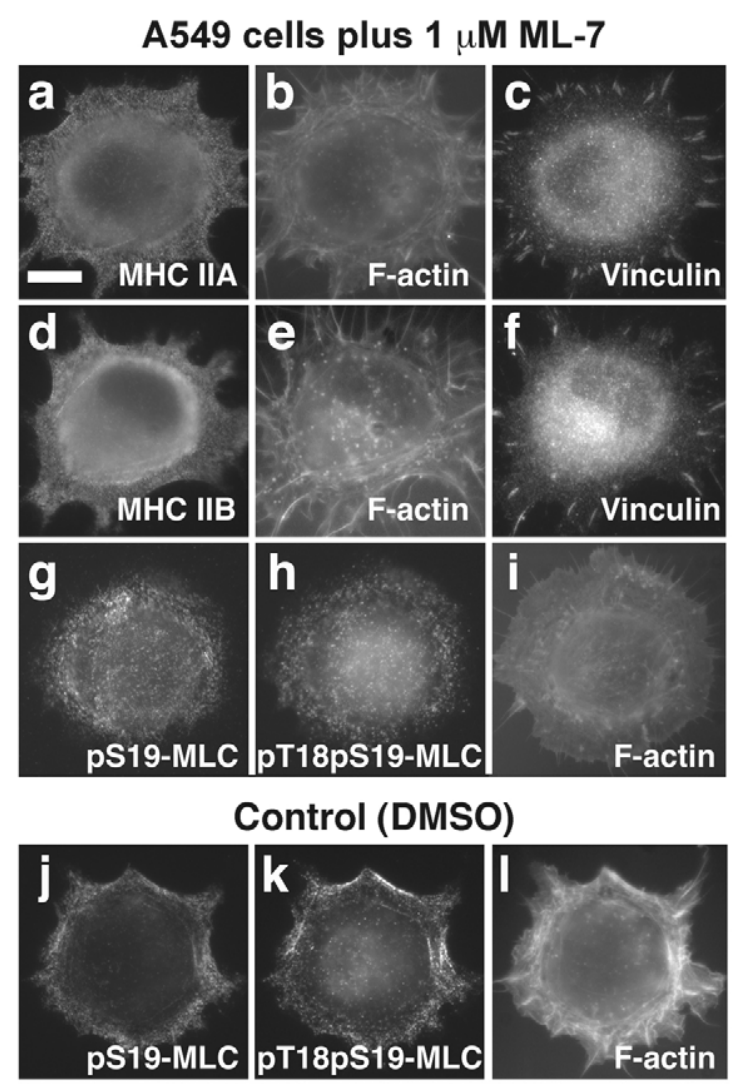

the absence of an effect of the Rho kinase inhibitor Y-27632 (Fig. 9D) were observed at all concentrations tested. These results suggest that SV might be slowing the rate of cell spreading by facilitating localized myosin II activation by MLCK.

To test the possibility of crosstalk between SV and MLCK, we co-transfected COS7 cells with plasmids encoding EGFPSV and Flag-tagged long and short isoforms of MLCK (L-
Fig. 8. Inhibition of MLCK mimics the effect of supervillin knockdown on the formation of peripheral bundles of activated myosin during spreading of A549 cells. A549 cells treated with 1 $\mu \mathrm{M}$ ML-7 to specifically inhibit MLCK (a-i) lack the peripheral bundles of activated myosin filaments found in control cells (j-1) after 30 minutes of spreading. Primary antibody staining for MHC IIA (a), vinculin (c,f), MHC IIB (d), pSer19-MLC (g,j) and pThr18pSer19MLC $(h, k)$ was visualized in the green $(\mathrm{a}, \mathrm{d}, \mathrm{h}, \mathrm{j})$ and red $(\mathrm{c}, \mathrm{f}, \mathrm{g}, \mathrm{k})$ channels. F-actin was visualized with Alexa-Fluor-350-phalloidin (b,e,i,l). Bar, $10 \mu \mathrm{m}$.

MLCK, S-MLCK; Fig. 10) (Blue et al., 2002; Herring et al., 2000). Murine L-MLCK contains the entire S-MLCK coding sequence. In addition, L-MLCK contains an extra N-terminal sequence of 954 amino acids with multiple actin-binding sites within its immunoglobulin (Ig) domains and two DXR repeats (repeats of a motif made up of the sequence DXRXXL) (Kudryashov et al., 2004; Poperechnaya et al., 2000; Smith et al., 2002; Stull et al., 1998; Yang et al., 2006). The shared SMLCK C-terminus contains another three DXR repeats, the kinase domain and a myosin II-binding site (Fig. 11A). A lysine-to-alanine mutation in the kinase domain generates kinase-dead (KD) MLCK mutants that inhibit the catalytic activity of MLCK (Wadgaonkar et al., 2003).

KD mutants of L-MLCK and S-MLCK and the wild-type forms all co-localized with EGFP-SV in peripheral myosin II and F-actin bundles during cell spreading (Fig. 10A). Colocalization was more pronounced for the L-MLCK proteins (Fig. 10A, panels a-h) than for the S-MLCK proteins (Fig. $10 \mathrm{~A}$, panels $\mathrm{i}-\mathrm{p}$ ) because of the high proportion of cytoplasmic S-MLCK (Blue et al., 2002; Poperechnaya et al., 2000).

To determine whether the SV-mediated effects on cell spreading require the unique L-MLCK $\mathrm{N}$-terminus, we determined the rates of spreading for COS7 cells co-transfected with each MLCK construct and either EGFP-SV or EGFP (Fig. 10B). Either wild-type L-MLCK or S-MLCK, when coexpressed with EGFP (Fig. 10B, columns 3, 7), mimicked EGFP-SV (Fig. 10B, column 2) in reducing the initial rates of
A MHC ATPase inhibitor
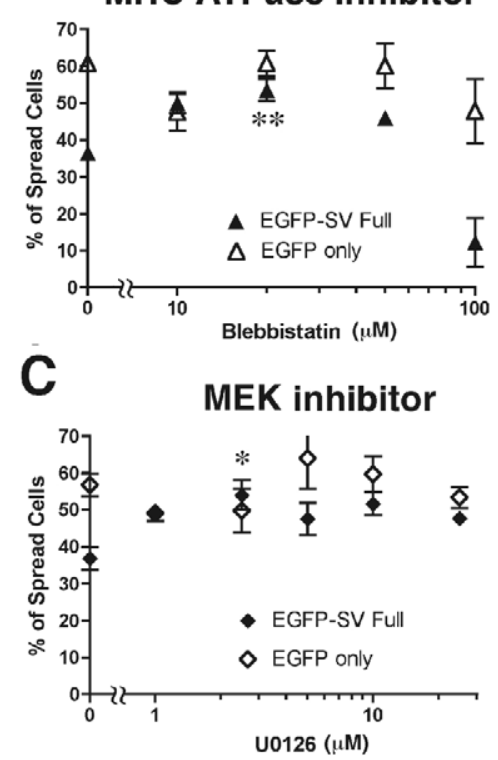
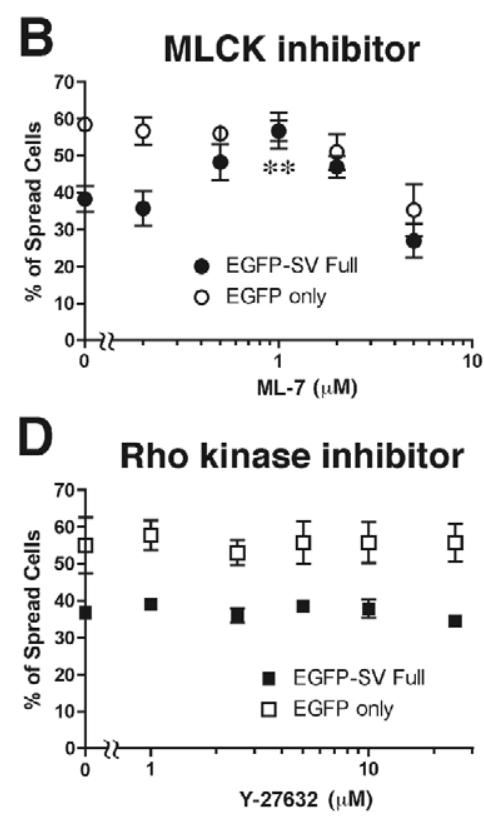

Fig. 9. At low concentrations, specific inhibitors of myosin II activity abolish supervillin-mediated decreases in spreading of COS7 cells. Percentages of spread COS7 cells expressing either EGFP-SV or EGFP at 30 minutes after plating on fibronectin in the presence of inhibitors of myosin function: (A) MHC ATPase inhibitor, blebbistatin, $* * P=0.003(20 \mu \mathrm{M}$ versus $0 \mu \mathrm{M}$ for EGFP-SV); (B) MLCK inhibitor, ML-7, **P=0.002 (1.0 $\mu \mathrm{M}$ versus $0 \mu \mathrm{M}$ for EGFP-SV); (C) MEK inhibitor, U0126, ${ }^{*} P=0.014(2.5 \mu \mathrm{M}$ versus $0 \mu \mathrm{M}$ for EGFP-SV); (D) Rho kinase inhibitor, Y-27632, no significant effects. Means \pm s.e.m.; 100 cells per data point per experiment, $n=4$. 
A
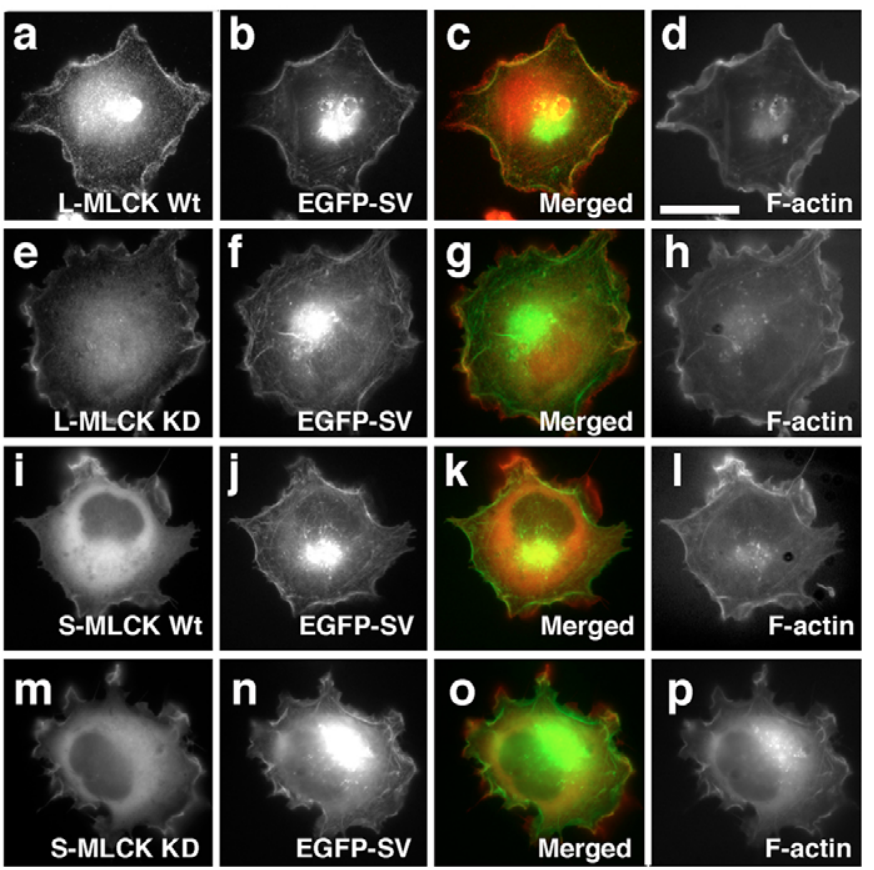

B

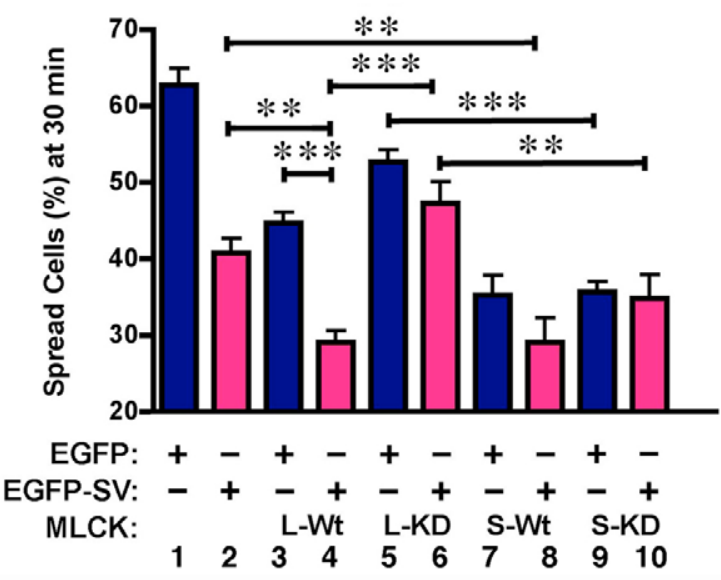

Fig. 10. MLCK isoforms, especially L-MLCK, co-localize with supervillin, and mimic and potentiate supervillin-mediated decreases in the rates of cell spreading. (A) Fluorescence micrographs of co-transfected COS7 cells after spreading on fibronectin for 30 minutes, showing Flag-tagged MLCK proteins, as indicated (a,e,i,m; red in merged images), EGFP-SV (b,f,j,n; green in merges) and merged images (c,g,k,o; overlap in yellow). MLCK proteins were visualized with anti-Flag antibodies and Alexa-Fluor594-conjugated anti-rabbit IgG antibodies; F-actin (d,h,l,p) was visualized with Alexa-Fluor-350-phalloidin. Bar, $20 \mu \mathrm{m}$. (B) Percentages of spread cells 30 minutes after plating on fibronectin for cells expressing: (1) EGFP only $(n=14)$; (2) EGFPSV only ( $n=14)$; (3) EGFP plus wild-type (Wt) L-MLCK $(n=6)$; (4) EGFP-SV plus wild-type L-MLCK ( $n=9)$; (5) EGFP plus L-MLCK KD $(n=6)$; (6) EGFP-SV plus L-MLCK KD (n=9); (7) EGFP plus wild-type S-MLCK $(n=6)$; (8) EGFP-SV plus wild-type S-MLCK $(n=9)$; (9) EGFP-SV plus S-MLCK KD $(n=6)$; or (10) EGFP-SV plus S-MLCK KD ( $n=9)$. Means \pm s.e.m.; 100 cells per experiment; $* * * P<0.001, * * P<0.01$. Statistical differences were evaluated using Student-Newman-Keuls multiple comparisons test. Notice that the $x$ axis starts at $20 \%$.
A

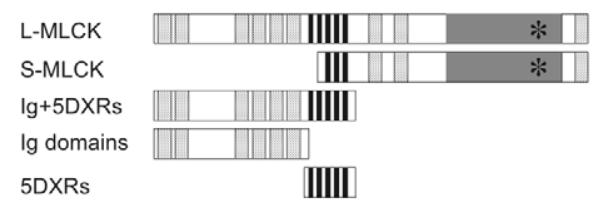

B

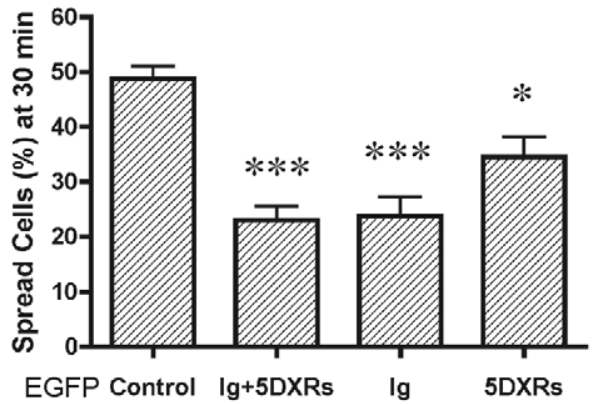

C

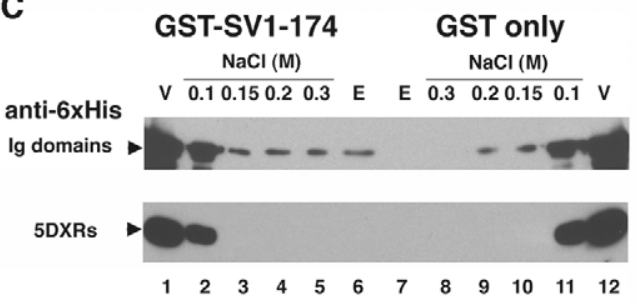

Fig. 11. L-MLCK N-terminal sequences reduce the rate of cell spreading and bind the SV N-terminus. (A) Diagram of L-MLCK, SMLCK and mutants. Catalytic core (dark gray); immunoglobulin-like domains (Ig, stippled); Asp-X-Lysine sequences (DXR, black); and location $(*)$ of the kinase-inactivating $(\mathrm{KD})$ point mutation are shown. (B) EGFP-tagged fusion proteins containing N-terminal LMLCK sequences (Poperechnaya et al., 2000) reduce the rate of cell spreading. N-terminal sequences unique to L-MLCK without (Ig) or with (Ig+5DXRs) all five of the DXRXXL actin-binding motifs reduce the rate of spreading by $\sim 50 \%$; the $5 \mathrm{DXR}$ motifs alone slow cell spreading by $\sim 30 \%$. Histogram of the percentages of spread COS7 cells transfected for 16 hours with EGFP as a control or EGFP-tagged avian L-MLCK sequences, as indicated.

Means \pm s.e.m.; 100 cells/experiment, $n=6 ; * P<0.05 ; * * * P<0.001$ versus EGFP-only control. (C) The L-MLCK Ig domains, but not the 5DXRs, bind directly to SV1-174. GST-tagged SV1-174 (lanes 1-6) or GST only (lanes 7-12) were pre-bound to glutathione-agarose beads and incubated with purified recombinant $6 \times$ His-tagged Ig domains (upper panel) or $6 \times$ His-tagged 5DXRs (lower panel). Void volumes $(\mathrm{V}$, lanes 1,12$)$, washes with the indicated concentrations of $\mathrm{NaCl}$ (lanes 2-5, 8-11) and glutathione eluates (E, lanes 6,7) were analyzed on immunoblots stained with anti- $6 \times$ His antibodies.

cell spreading (column 1). Co-expression of either wild-type MLCK isoform with EGFP-SV accentuated SV-mediated reductions in the rate of cell spreading (Fig. 10B, columns 4 and 8 versus column 2). As shown in Fig. 10B, KD L-MLCK (columns 5, 6) was less effective than wild-type L-MLCK (columns 3,4 ) at reducing spreading rates for EGFPexpressing cells (column 1) and did not accentuate the effects of EGFP-SV (column 2). By contrast, KD S-MLCK (columns 9,10 ) exhibited an effect similar to that of wild-type S-MLCK (columns 7,8 ). Neither effect was significantly altered by the 

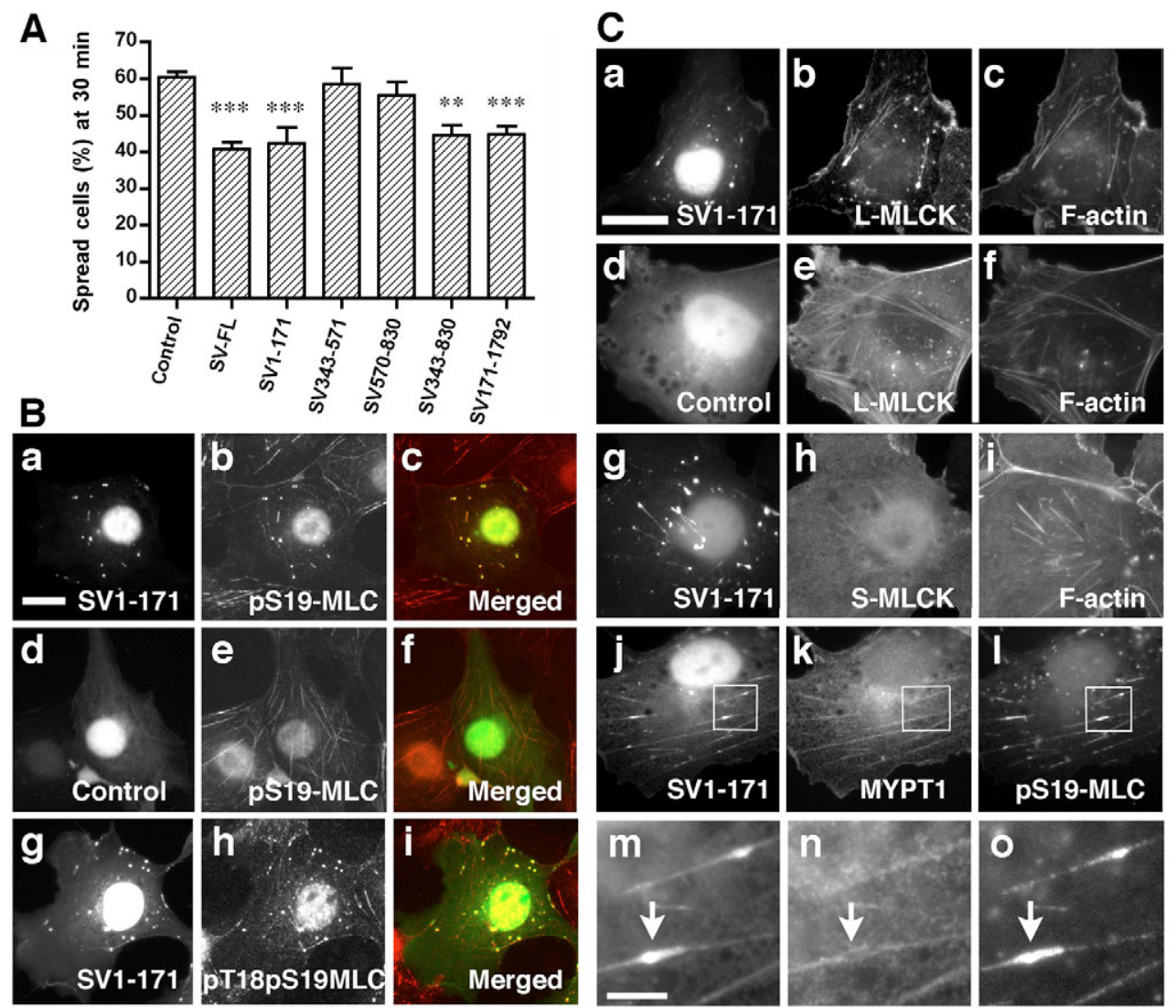

Fig. 12. Both F-actin-bundling and myosin II-binding sequences in supervillin slow cell spreading; SV1-171 co-localizes with mono- and diphosphorylated MLC and L-MLCK, but not with S-MLCK or with the MYPT1 subunit of myosin phosphatase. (A) Percentages of spread COS7 cells transfected with EGFP (Control) or EGFP-SV: full length (SV-FL), SV1-171, SV343-571, SV570-830, SV343-830, SV171-1792. Means \pm s.e.m.; $n=6 ; * * * P<0.001$ versus EGFP control; $* * P<0.01$ versus EGFP control. (B) COS7 cells transfected with EGFP-SV1-171 (SV1171, a,g; green in c,i) or EGFP only (Control, d; green in f) and counterstained with anti-phosphoSer19-MLC antibodies (pS19-MLC, b,e; red in c,f) or antibody against pThr18pSer19-MLC (h; red in i). Overlap in merged images (c,f,i) appears yellow. Bar, $20 \mu \mathrm{m}$. (C) Co-transfected COS7 cells expressing EGFP-SV1-171 (SV1-171, a,g) or EGFP only (Control, d) and Flag-tagged L-MLCK (b,e) or S-MLCK (h) and counterstained with Alexa-Fluor-350-phalloidin (c,f,i). Cells expressing EGFP-SV1-171 alone (j,m) were stained with antibodies against the MYPT1 subunit of myosin phosphatase $(\mathrm{k}, \mathrm{n})$ and phosphoS19-MLC $(1, \mathrm{o})$. (m-o) Enlargements of the boxed areas in $\mathrm{j}-1$. Arrows show punctae of SV1-171 with pS19-MLC that lack MYPT1. Bars, $20 \mu \mathrm{m}$ (a-1); $5 \mu \mathrm{m}$ (m-o).

presence of EGFP-SV (columns 7 versus 8; 9 versus 10), implying a kinase- and SV-independent mechanism. The differences between the effects of KD L-MLCK and KD SMLCK (columns 9 versus 5; 10 versus 6) suggest an additional kinase-independent effect associated with the unique L-MLCK $\mathrm{N}$-terminus. Thus, these results are consistent with involvement of SV in an L-MLCK-mediated kinase-dependent mechanism and with one or more kinase-independent effects in the rate of cell spreading induced by S-MLCK (the L-MLCK C-terminus) and by L-MLCK N-terminal sequences.

Multiple mechanisms are supported by domain-mapping studies of L-MLCK and EGFP-tagged SV sequences (Figs 11, 12). Consistent with a kinase-independent mechanism, LMLCK-specific N-terminal sequences (Fig. 11A), which lack the myosin-binding and kinase domains (Stull et al., 1998) but bundle actin filaments (Smith et al., 2002; Yang et al., 2006), slowed the rate of cell spreading by $30-53 \%$ (Fig. 11B). A $\sim 26 \%$ reduction was also observed with the SV fragments that can bundle F-actin (Chen et al., 2003), SV343-830 and SV1711792 (Fig. 12A).
However, F-actin bundling cannot be the sole mechanism by which SV reduces the rate of cell spreading. The Nterminal 171 residues in SV (SV1-171), which do not bind Factin but do bind to myosin II (Chen et al., 2003) and to the L-MLCK N-terminal Ig domains (Fig. 11C), also slowed cell spreading (Fig. 12A). In addition, EGFP-tagged SV1-171 induces the formation of myosin punctae (Chen et al., 2003) that co-localize with mono- and di-phosphorylated MLC (Fig. 12B) and with L-MLCK (Fig. 12C, panels a-c). S-MLCK was far less efficiently associated (Fig. 12C, panels g-i), and these structures appeared to actually exclude the myosin phosphatase subunit MYPT1 (Fig. 12C, panels j-l). Timelapse imaging of EGFP-SV1-171 showed that the elongated punctae arise from apparently hypercontractile segments of stress fibers (supplementary material Movie 3). Taken together, these results suggest that F-actin bundling is responsible for at least some of the kinase-independent reductions in cell spreading and implicate SV1-171 in a kinase-dependent mechanism involving myosin II activation by L-MLCK. 


\section{Discussion}

We demonstrate here that SV decreases the rate of cell spreading via interactions with myosin II, F-actin and LMLCK. SV co-localized with F-actin and myosin II filament bundles at the plasma membrane, and SV levels correlated with the extent of bundle formation during initial cell spreading. SV binds directly to myosin IIA and myosin IIB and to the Nterminus of L-MLCK, as well as to actin filaments (Chen et al., 2003). SV-associated filament bundles are enriched in LMLCK and, to a lesser extent, in S-MLCK. Pharmacological inhibition of MLCK or myosin motor activity reverses the SVmediated decreases in the rate of cell spreading, and MLCK overexpression phenocopies the SV effect. Cell spreading is slowed by L-MLCK and SV sequences that bundle F-actin. Cell spreading is also slowed by SV1-171, which binds myosin II and L-MLCK in vitro and co-localizes with aggregates of LMLCK and activated myosin II in vivo. Thus, SV apparently modulates cell spreading by promoting or stabilizing actomyosin bundles and/or upregulating myosin II activation at the plasma membrane.

The major new finding reported here is that $\mathrm{SV}$, a membrane protein, enhances L-MLCK-mediated myosin II function during cell spreading. Others have used myosin II inhibitors, including blebbistatin, to show that myosin II plays an active role in promoting cell spreading (Betapudi et al., 2006; Cramer and Mitchison, 1995; Duxbury et al., 2004; Sumoza-Toledo et al., 2006; Wakatsuki et al., 2003). Inhibition of MLCK with high concentrations $(\geqslant 5 \mu \mathrm{M})$ of ML-7 slows cell spreading (Betapudi et al., 2006; Giannone et al., 2004). We show here that SV introduces a biphasic nature to the inhibitor doseresponse curves (Figs 7, 9) consistent with SV-mediated enhancement of myosin II-mediated contractility that antagonizes cell spreading. Low concentrations of either blebbistatin $(20 \mu \mathrm{M})$ or ML-7 $(1 \mu \mathrm{M})$ alleviate the SVmediated effect, returning the rate of cell spreading to that observed with lower SV levels. These results suggest that subpopulations of myosin II and MLCK, distinguished by myosin isoform and/or associated proteins, might be differentially sensitive to low concentrations of these drugs and/or to regulation by SV.

Our results also suggest that SV is part of an interconnected membrane-associated scaffold that helps position myosin II and F-actin with respect to MLCK. Myosin II and actin filaments have long been known to assemble at the membrane surface (DeBiasio et al., 1988; McKenna et al., 1989; Rhee et al., 1994) and to interact with both L-MLCK and S-MLCK (Blue et al., 2002; Dulyaninova et al., 2004; Poperechnaya et al., 2000; Stull et al., 1998). The additional F-actin-binding and -bundling sequences in the unique L-MLCK N-terminus apparently increase the affinity of L-MLCK, relative to SMLCK, for actin filaments (Smith et al., 2002; Yang et al., 2006). SV also binds to both myosin and actin filaments, with the physical separation of the F-actin- and myosin II-binding sites within SV consistent with its suggested potential for regulated recruitment of actin and myosin filaments during myofibril and stress fiber assembly at the membrane (Oh et al., 2003).

An interaction of SV with the N-terminus of L-MLCK is suggested by direct binding in vitro and by the preferential colocalization of L-MLCK with SV1-171 in vivo. Simultaneous binding of SV1-171 to myosin and to L-MLCK could provide the basis for SV-mediated activation of myosin II by helping to retain or position L-MLCK on the myosin II heavy chain.

An SV-associated scaffold could mediate local MLCK activation via phosphorylation by ERK during cell spreading (Huang et al., 2004; Klemke et al., 1997). This possibility is consistent with the ability of the MEK inhibitor U0126 to reverse SV-mediated effects on cell spreading (Fig. 9) and with the co-localization of SV, myosin II and ERK in smooth muscle cells (Gangopadhyay et al., 2004). The suggestion that ERK signaling might be regulated by SV is also consistent with the observation that ERK activation during agonist-mediated contraction is inhibited by knockdown of the smooth muscle isoform of SV in ferret aorta (Gangopadhyay et al., 2004). The interaction between SV and calponin (Gangopadhyay et al., 2004) - a protein that binds directly to F-actin, myosin II and ERK (Leinweber et al., 1999; Morgan and Gangopadhyay, 2001) - suggests a further level of interconnection.

A second possible mechanism is that the binding of SV1171 to subfragment 2 of myosin regulates its conformation and thus increases the affinity of L-MLCK for the myosin head-rod junction (Masato et al., 1997). For example, SV1-171 binding to myosin might promote myosin monomer unfolding and thus facilitate myosin activation by MLC phosphorylation and subsequent filament assembly (Kolega, 1998; Kolega and Taylor, 1993). Conversely, SV might stabilize the myosin filament or block myosin filament disassembly. For instance, by binding to subfragment 2 of myosin, SV might block binding of myosin phosphatase to this site (Johnson et al., 1997; Mitsui et al., 1992), shifting the dynamic equilibrium of dephosphorylated versus phosphorylated MLC and leading to the observed exclusion of MYPTI and the accumulation of mono- and di-phosphorylated MLC with SV and SV1-171 (Fig. 12).

SV might also stabilize contractile assemblies by bundling and thus stabilizing actin filaments against disassembly. This hypothesis is consistent with the observations that the actinbundling fragments of SV and L-MLCK decrease the rate of cell spreading. This possibility is also consistent with recent work showing that myosin II slows cell protrusion by accelerating actin filament fragmentation in a contractile zone away from the leading edge (Medeiros et al., 2006), a process that is antagonized by actin filament stabilization, such as by tropomyosin (Huckaba et al., 2006). Given the sequence similarity between the SV C-terminus and the actin filamentsevering proteins villin and gelsolin (Pestonjamasp et al., 1997), SV-mediated filament stabilization might seem unlikely. However, sequences required for F-actin severing in gelsolin and villin (Matsudaira et al., 1985) are absent from SV (Pestonjamasp et al., 1997; Wulfkuhle et al., 1999).

Another possibility is that the combined F-actin and myosin II binding capabilities of SV regulate the actomyosin crossbridge cycle in the way proposed for calponin and caldesmon (Szymanski, 2004). Smooth muscle isoforms of these proteins are thought to act as 'latch bridges' that inhibit myosin crossbridge cycling while binding to both F-actin and activated myosin II, stabilizing the contractile state. In this model, SV1171 competes for binding on myosin subfragment 2 with endogenous full-length SV and/or nonmuscle caldesmon, releasing the latch state and inducing the localized contractions that apparently destabilize stress fiber integrity (supplementary material Movie 3). 
These possible modes of action are not mutually exclusive because SV regulation of actin-myosin interactions at the membrane might differ with intracellular location. For instance, SV might promote myosin activation in the posited signaling scaffold with L-MLCK at the cell periphery (Medeiros et al., 2006) and inhibit myosin II function elsewhere. SV1-171 and SV343-571 both reduce the number of large focal adhesions in the center of the cell (Takizawa et al., 2006). The effect of SV1-171 is consistent with a role for SV in potentiating L-MLCK-induced focal adhesion disassembly at various intracellular sites (Webb et al., 2004), but the lack of effect of SV343-571 on cell spreading (Fig. 12) argues strongly for a second regulatory mechanism. In fact, SV343-571 decreases cell-substrate adhesion via an interaction with the focal adhesion protein TRIP6, which leads to loss of stress fibers and of mature focal adhesions in the cell interior (Takizawa et al., 2006). Thus, SV apparently participates in at least two regulated interactions involving myosin II, F-actin and focal adhesion proteins at different intracellular locations during different stages of cell migration.

\section{Materials and Methods \\ Chemicals}

Glutathione-Sepharose was purchased from Amersham Biosciences (Piscataway, NJ). ML-7 was from Calbiochem-Novabiochem (La Jolla, CA). Blebbistatin with a \pm stereochemical ratio of 1:1 was from Tocris (Bristol, UK). U0126 was from Sigma (St Louis, MO). Y-27632 was from Yoshitomi Pharmaceutical Industries (Osaka, Japan). Other chemicals were from Sigma, Calbiochem-Novabiochem, Fisher (Pittsburgh, PA) or VWR International (Bristol, CT).

\section{Antibodies}

Rabbit polyclonal anti-nonmuscle MHC IIA, rabbit polyclonal anti-nonmuscle MHC IIB, sheep polyclonal anti-MLCK and rabbit polyclonal anti-MYPT1 were from BAbco-Covance (Richmond, CA). Rabbit polyclonal anti-ERK1/2 was from Upstate (Lake Placid, NY). Mouse monoclonal anti- $\beta$-tubulin (TUB2.1), mouse monoclonal vinculin (hVIN1) and rabbit polyclonal anti-Flag were from Sigma. Mouse monoclonal anti-phospho-Ser19 MLC, rabbit polyclonal anti-phosphoThr18/Ser19 MLC and mouse monoclonal anti-6×His (27E8) were from Cell Signaling Technology (Beverly, MA). Goat polyclonal anti-GST antibodies were from Amersham. Horseradish peroxidase (HRP)-conjugated secondary antibodies against rabbit, mouse and goat/sheep IgGs were from Jackson ImmunoResearch (West Grove, PA). Rabbit polyclonal anti-SV (H340) has been described (Nebl et al., 2002; Oh et al., 2003).

\section{Mammalian expression vectors}

EGFP-SV and EGFP-SV fragment vectors were described previously (Chen et al., 2003; Wulfkuhle et al., 1999). EGFP-SV171-1792 was made by ligating the fragment released from EGFP-SV171-571 with AgeI into AgeI-digested EGFP-SV (Chen et al., 2003). Plasmids encoding Flag-tagged wild-type and KD murine 220 kDa L-MLCK and Flag-tagged rabbit 130 kDa S-MLCK were gifts from Patricia Gallagher (Indiana University School of Medicine, IN) (Blue et al., 2002). Constructs encoding EGFP-tagged N-terminal fragments of human L-MLCK (amino acids 2-867 and 2-1024) and EGFP-tagged rabbit five DXR actin-binding domains (Smith et al., 2002) were provided by Anne R. Bresnick (Albert Einstein College of Medicine, Bronx, NY) (Dulyaninova et al., 2004).

\section{Recombinant proteins}

GST tagged SV1-174 was described previously (Chen et al., 2003). The S2 domains of human nonmuscle myosin IIA (NP002464, coding amino acid sequences 8371188, LLQVSRQ-THEAQIQ), human nonmuscle myosin IIB (NP005955, coding amino acid sequences 844-1192, LLQVTRQ-ETKNHEA) and human skeletal muscle myosin II (NP005954, coding amino acid sequences 843-1246, LLKSAETETVSKAK) were subcloned into the pFastBac1 vector (Invitrogen, Carlsbad, CA) with a C-terminal hexa-histidine $(6 \times$ His $)$ tag. The Ig and five DXR domains from L-MLCK were expressed with $\mathrm{N}$-terminal $6 \times$ His tags using the pet30a vector (Novagen). $6 \times$ His-tagged myosin II S2 domains and MLCK proteins were expressed in Sf9 cells and BL21(DE3)LysS, respectively, and purified with $\mathrm{Ni}^{2+} \mathrm{NTA}$ agarose columns (Qiagen, Valencia, CA), according to the manufacturer's protocol.

\section{Cell culture and transfection}

COS7-2 cells, a highly transfectable clone of COS7 (Kowalczyk et al., 1997), were a generous gift from Kathleen J. Green (Northwestern University, IL). COS7-2 cells were grown in Dulbecco's Modified Eagle high glucose media (DME) supplemented with $10 \%$ fetal calf serum (FCS) for $\leqslant 20$ passages. A549 human nonsmall cell lung carcinoma cells [American Type Culture Collection (ATCC), Rockville, MD] were maintained in Ham's F12K medium, 2 mM L-glutamine, 10\% FCS for up to 12 passages.

Transfection methods have been described (Takizawa et al., 2006). Briefly, COS7 cells were transfected using Effectene Transfection Reagent (Qiagen) for 24 hours, except in experiments with L-MLCK N-terminal sequences, which were lethal to cells transfected for longer than 16 hours (Dulyaninova et al., 2004). A549 cells at $\sim 60 \%$ confluence were transfected twice with $10 \mathrm{nM}$ dsRNA and Lipofectamine 2000, as recommended (Invitrogen), and grown for 4 days. Two dsRNAs targeting human SV were made as Stealth duplexes (Invitrogen): human (h)SV1, 5'CAGCCAUAAGGAAUCUAAAUAUGCU-3' (coding nucleotides 1680-1704) and hSV2, 5' -GCGAUGUUUGCUGCUGGAGAGAUCA-3' (coding nucleotides 20262050). The Stealth duplex sequence, $5^{\prime}$-GAACUAUGAAGGACCACCAGAGAUA$3^{\prime}$, was used as a control dsRNA. Cell growth was similar for mock and dsRNAitreated cells (data not shown).

\section{Cell-spreading assay}

Cells were cultured in T25 tissue culture flasks $\left(25 \mathrm{~cm}^{2}\right)$ and detached by incubating at $37^{\circ} \mathrm{C}$ for 2 minutes with $0.5 \mathrm{ml}$ trypsin/EDTA solution $(0.1 \% / 0.40 \mathrm{mg} / \mathrm{ml}$ for COS7 cells, or $0.25 \% / 1.0 \mathrm{mg} / \mathrm{ml}$ for A549 cells). Trypsin was immediately neutralized with $5 \mathrm{ml}$ culture medium containing $5 \mu \mathrm{g} / \mathrm{ml}$ aprotinin, and the cells were washed once with $10 \mathrm{ml}$ PBS, $\mathrm{pH}$ 7.2-7.4. Cells were adjusted to $3.0 \times 10^{4}$ cells $/ \mathrm{ml}$ of serum- and antibiotic-free media $(2.5 \mathrm{ml} /$ well for COS7 cells, or 2.0 $\mathrm{ml} /$ well for A549 cells), and were transferred into wells $\left(9.60 \mathrm{~cm}^{2}\right)$ of six-well plates containing $18 \times 18 \mathrm{~mm}$ coverslips coated with $10 \mu \mathrm{g} / \mathrm{ml}$ bovine plasma fibronectin (Sigma). For experiments with chemical inhibitors, $2 \times$ concentrations of cells were added to wells containing equal amounts of media with $2 \times$ concentrations of inhibitors. At each time point, cells were fixed with $4 \%$ paraformaldehyde and counted using a $40 \times$ Pan-NeoFluor oil immersion objective (NA 1.3) with phasecontrast optics on a Zeiss Axioskop microscope (Carl Zeiss MicroImaging, Thornwood, NY)

\section{Immunofluorescence microscopy}

Methods for indirect immunofluorescence microscopy have been described previously (Chen et al., 2003; Takizawa et al., 2006). Briefly, cells were fixed for 20 minutes with $4 \%$ paraformaldehyde in PBS, $1 \mathrm{mM} \mathrm{MgCl}_{2}, 1 \mathrm{mM}$ EGTA and permeabilized for 5 minutes with $0.1 \%$ Triton X-100, PBS before immunostaining. Depending on the experiment, cells were stained for nonmuscle MHC IIA (1:400 dilution), MHC IIB (1:400), $\beta$-tubulin (1:400), vinculin (1:200), phospho-Ser19 MLC (1:200), phospho-Thr18/Ser19 MLC (1:200), MYPT1 (1:100), Flag (1:100), and/or SV (1:100). Cross-adsorbed secondary antibodies, conjugated with AlexaFluor-350, -488, or -594 were from Invitrogen Molecular Probes (Eugene, OR). Factin was visualized with phalloidin conjugated to Texas-Red or Alexa-Fluor-350 (Molecular Probes). Slides were analyzed with a $100 \times$ Pan-NeoFluar oil immersion objective (NA 1.3) on a Zeiss Axioskop fluorescence microscope with a RETIGA 1300 CCD camera (QImaging Corp., Burnsby BC, Canada) and OpenLab software (Improvision, Lexington, MA). Each channel of the epifluorescence micrographs was scaled automatically using the Auto Level submenu in Adobe Photoshop 7.0 (San Jose, CA). Due to the high background in Alexa-Fluor-350-phalloidin images (Figs 3, 6, 8, 10, 12; supplementary material Figs S2, S3, S4), background was subtracted after Auto Level manipulation. This operation might also remove weak Alexa-Fluor-350 signals. Image intensity profiles were obtained using the Plot Profile subprogram in ImageJ 1.37v (NIH, Bethesda, MD).

\section{Live-cell imaging}

dsRNA-transfected A549 cells were allowed to settle onto fibronectin (10 $\mu \mathrm{g} / \mathrm{ml})$ coated $35 \mathrm{~mm}$ chambers (FluoroDish, World Precision Instruments, Sarasota, FL) containing $3 \mathrm{ml}$ DME without phenol red on a DMIRE 2 inverted microscope (Leica Microsystems, Allendale, NJ) in a Plexiglass environmental chamber heated to $37^{\circ} \mathrm{C}$. Phase contrast images of the chamber surface were acquired with an HC PL $\mathrm{Ph} 2,20 \times, 0.50 \mathrm{NA}$, air objective lens and a Retiga Exi cooled CCD camera (QImaging), using Open Lab 3.5.2 software (Movies 1, 2). EGFP-SV1-171transfected COS7 cells on square coverslips $(22 \mathrm{~mm})$ in a chamber containing DME $+10 \%$ FCS without phenol red were visualized similarly using an HCX PL Apo, $63 \times, 1.32 \mathrm{NA}$, oil immersion objective lens (Movie 3). Images were processed with OpenLab to generate movie files.

\section{L-MLCK- and myosin-binding assays}

Binding assays with myosin II S2 domains have been described (Chen et al., 2003). Briefly, $6 \times$ His-tagged myosin S2 domains $(100 \mu \mathrm{g})$ were incubated for 1 hour at $4^{\circ} \mathrm{C}$ with glutathione-Sepharose $(50 \mu \mathrm{l})$ containing pre-bound GST-SV1-174 or GST $(100 \mu \mathrm{g})$ proteins in binding buffer (10 mM MOPS, pH 7.5, $1 \mathrm{mM}$ ATP, 5 $\mathrm{mM} \mathrm{MgCl} 2,50 \mathrm{mM} \mathrm{NaCl}, 0.05 \% \beta$-mercaptoethanol). Beads were transferred to a $2 \mathrm{ml}$ column, and the columns were washed with $0.5 \mathrm{ml}$ of binding buffer and then with $100-\mu l$ portions of binding buffer containing increasing concentrations $(0.1$, 
$0.15,0.2$ and $0.3 \mathrm{M})$ of $\mathrm{NaCl}$. Binding assays with L-MLCK fragments $(100 \mu \mathrm{g})$ were performed similarly, except that the binding buffer was $10 \mathrm{mM}$ MOPS, 100 $\mathrm{mM}$ imidazole, $\mathrm{pH} 7.5,100 \mathrm{mM} \mathrm{KCl}, 50 \mu \mathrm{M}$ EGTA, 0.05\% $\beta$-mercaptoethanol, $3.25 \%$ glycerol, and the column was washed with $0.25 \mathrm{ml}$ portions of a buffer containing $20 \mathrm{mM}$ MOPS, $20 \mathrm{mM}$ imidazole, $\mathrm{pH} 7.5,0.1 \mathrm{mM}$ EGTA, $0.1 \% \beta$ mercaptoethanol with increasing concentrations $(0.1,0.1,0.15,0.2$ and $0.3 \mathrm{M})$ of $\mathrm{NaCl}$. GST proteins and bound myosin or L-MLCK fragments were eluted from the washed columns with $250 \mu \mathrm{l}$ of $5 \mathrm{mM}$ glutathione in washing buffer with $0.3 \mathrm{M}$ $\mathrm{NaCl}$. Fractionated proteins were analyzed by immunoblot analysis using anti-GST antibodies (goat polyclonal; 1:1000; Amersham) and anti- $6 \times$ His antibodies (mouse clone 27E8; 1:1000).

\section{Immunoblotting and SDS-PAGE}

SDS-PAGE and immunoblotting have been described (Takizawa et al., 2006). Primary antibodies and dilutions: anti-SV (H340), 1:10,000; anti-MHC IIA, 1:10,000; anti-MHC IIB, 1:10,000; anti-MLCK, 1:3000; anti-ERK1/2, 1:3000; antiGST, 1:1000; and 6×His, 1:1000. HRP-conjugated secondary antibodies and dilutions: anti-rabbit IgG, 1:10,000; anti-mouse IgG, 1:10,000; anti-goat/sheep IgG; $1: 10,000$.

Research was supported by NIH grants GM33048 to E.J.L., and AR41653 and HL073050 to M.I. We thank Patricia Gallagher and Anne Bresnick for the gifts of MLCK plasmids, and Fumio Matsumura for antibody against phosphorylated MLC used in preliminary experiments. We also thank Anne Bresnick, Fumio Matsumura, Tara Smith and Jessica Crowley for critical reading of the manuscript, and Louise Ohrn and Donna Castellanos for technical assistance.

\section{References}

Amano, M., Ito, M., Kimura, K., Fukata, Y., Chihara, K., Nakano, T., Matsuura, Y. and Kaibuchi, K. (1996). Phosphorylation and activation of myosin by Rho-associated kinase (Rho-kinase). J. Biol. Chem. 271, 20246-20249.

Bain, J., McLauchlan, H., Elliott, M. and Cohen, P. (2003). The specificities of protein kinase inhibitors: an update. Biochem. J. 371, 199-204.

Bao, J., Jana, S. S. and Adelstein, R. S. (2005). Vertebrate nonmuscle myosin II isoforms rescue small interfering RNA-induced defects in COS-7 cell cytokinesis. J. Biol. Chem. 280, 19594-19599.

Beningo, K. A., Hamao, K., Dembo, M., Wang, Y. L. and Hosoya, H. (2006). Traction forces of fibroblasts are regulated by the Rho-dependent kinase but not by the myosin light chain kinase. Arch. Biochem. Biophys. 456, 224-231.

Betapudi, V., Licate, L. S. and Egelhoff, T. T. (2006). Distinct roles of nonmuscle myosin II isoforms in the regulation of MDA-MB-231 breast cancer cell spreading and migration. Cancer Res. 66, 4725-4733.

Blue, E. K., Goeckeler, Z. M., Jin, Y., Hou, L., Dixon, S. A., Herring, B. P., Wysolmerski, R. B. and Gallagher, P. J. (2002). 220- and 130-kDa MLCKs have distinct tissue distributions and intracellular localization patterns. Am. J. Physiol. Cell Physiol. 282, C451-C460.

Bretscher, M. S. (1996). Getting membrane flow and the cytoskeleton to cooperate in moving cells. Cell 87, 601-606.

Bridgman, P. C., Dave, S., Asnes, C. F., Tullio, A. N. and Adelstein, R. S. (2001). Myosin IIB is required for growth cone motility. J. Neurosci. 21, 6159-6169.

Brown, M. E. and Bridgman, P. C. (2003). Retrograde flow rate is increased in growth cones from myosin IIB knockout mice. J. Cell Sci. 116, 1087-1094.

Cai, Y., Biais, N., Giannone, G., Tanase, M., Jiang, G., Hofman, J. M., Wiggins, C. H., Silberzan, P., Buguin, A., Ladoux, B. et al. (2006). Nonmuscle myosin IIAdependent force inhibits cell spreading and drives F-actin flow. Biophys. J. 91, 39073920 .

Chen, Y., Takizawa, N., Crowley, J. L., Oh, S. W., Gatto, C. L., Kambara, T., Sato, O., Li, X., Ikebe, M. and Luna, E. J. (2003). F-actin and myosin II binding domains in supervillin. J. Biol. Chem. 278, 46094-46106.

Chew, T. L., Wolf, W. A., Gallagher, P. J., Matsumura, F. and Chisholm, R. L. (2002). A fluorescent resonant energy transfer-based biosensor reveals transient and regional myosin light chain kinase activation in lamella and cleavage furrows. J. Cell Biol. 156, 543-553.

Choi, O. H., Adelstein, R. S. and Beaven, M. A. (1994). Secretion from rat basophilic RBL-2H3 cells is associated with diphosphorylation of myosin light chains by myosin light chain kinase as well as phosphorylation by protein kinase C. J. Biol. Chem. 269, 536-541.

Connell, L. E. and Helfman, D. M. (2006). Myosin light chain kinase plays a role in the regulation of epithelial cell survival. J. Cell Sci. 119, 2269-2281.

Cramer, L. P. and Mitchison, T. J. (1995). Myosin is involved in postmitotic cell spreading. J. Cell Biol. 131, 179-189.

DeBiasio, R. L., Wang, L.-L., Fisher, G. W. and Taylor, D. L. (1988). The dynamic distribution of fluorescent analogues of actin and myosin in protrusions at the leading edge of migrating Swiss 3 T3 fibroblasts. J. Cell Biol. 107, 2631-2645.

Dubin-Thaler, B. J., Giannone, G., Döbereiner, H.-G. and Sheetz, M. P. (2004). Nanometer analysis of cell spreading on matrix-coated surfaces reveals two distinct cell states and STEPs. Biophys. J. 86, 1794-1806.
Dulyaninova, N. G., Patskovsky, Y. V. and Bresnick, A. R. (2004). The N-terminus of the long MLCK induces a disruption in normal spindle morphology and metaphase arrest. J. Cell Sci. 117, 1481-1493.

Duxbury, M. S., Ashley, S. W. and Whang, E. E. (2004). Inhibition of pancreatic adenocarcinoma cellular invasiveness by blebbistatin: a novel myosin II inhibitor. Biochem. Biophys. Res. Commun. 313, 992-997.

El-Mezgueldi, M. and Marston, S. B. (1996). The effects of smooth muscle calponin on the strong and weak myosin binding sites of F-actin. J. Biol. Chem. 271, 2816128167.

Fazal, F., Gu, L., Ihnatovych, I., Han, Y., Hu, W., Antic, N., Carreira, F., Blomquist, J. F., Hope, T. J., Ucker, D. S. et al. (2005). Inhibiting myosin light chain kinase induces apoptosis in vitro and in vivo. Mol. Cell. Biol. 25, 6259-6266.

Fincham, V. J., James, M., Frame, M. C. and Winder, S. J. (2000). Active ERK/MAP kinase is targeted to newly forming cell-matrix adhesions by integrin engagement and v-Src. EMBO J. 19, 2911-2923.

Gangopadhyay, S. S., Takizawa, N., Gallant, C., Barber, A. L., Je, H. D., Smith, T. C., Luna, E. J. and Morgan, K. G. (2004). Smooth muscle archvillin: a novel regulator of signaling and contractility in vascular smooth muscle. J. Cell Sci. 117, 5043-5057.

Giannone, G., Dubin-Thaler, B. J., Dobereiner, H. G., Kieffer, N., Bresnick, A. R. and Sheetz, M. P. (2004). Periodic lamellipodial contractions correlate with rearward actin waves. Cell 116, 431-443.

Gupton, S. L. and Waterman-Storer, C. M. (2006). Spatiotemporal feedback between actomyosin and focal-adhesion systems optimizes rapid cell migration. Cell 125, 13611374.

Herring, B. P., Dixon, S. and Gallagher, P. J. (2000). Smooth muscle myosin light chain kinase expression in cardiac and skeletal muscle. Am. J. Physiol. Cell Physiol. 279, C1656-C1664.

Huang, C., Jacobson, K. and Schaller, M. D. (2004). MAP kinases and cell migration. J. Cell Sci. 117, 4619-4628.

Huckaba, T. M., Lipkin, T. and Pon, L. A. (2006). Roles of type II myosin and a tropomyosin isoform in retrograde actin flow in budding yeast. J. Cell Biol. 175, 957969.

Ikebe, M. (1989). Phosphorylation of a second site for myosin light chain kinase on platelet myosin. Biochemistry 28, 8750-8755.

Ikebe, M., Koretz, J. and Hartshorne, D. J. (1988). Effects of phosphorylation of light chain residues threonine 18 and serine 19 on the properties and conformation of smooth muscle myosin. J. Biol. Chem. 263, 6432-6437.

Ito, M., Nakano, T., Erdodi, F. and Hartshorne, D. J. (2004). Myosin phosphatase: structure, regulation and function. Mol. Cell. Biochem. 259, 197-209.

Itoh, K., Hara, T. and Shibata, N. (1992). Diphosphorylation of platelet myosin by myosin light chain kinase. Biochim. Biophys. Acta 1133, 286-292.

Johnson, D., Cohen, P., Chen, M. X., Chen, Y. H. and Cohen, P. T. (1997). Identification of the regions on the M110 subunit of protein phosphatase $1 \mathrm{M}$ that interact with the M21 subunit and with myosin. Eur. J. Biochem. 244, 931-939.

Jurado, C., Haserick, J. R. and Lee, J. (2005). Slipping or gripping? Fluorescent speckle microscopy in fish keratocytes reveals two different mechanisms for generating a retrograde flow of actin. Mol. Biol. Cell 16, 507-518.

Kim, M., Jiang, L. H., Wilson, H. L., North, R. A. and Surprenant, A. (2001). Proteomic and functional evidence for a $\mathrm{P} 2 \mathrm{X} 7$ receptor signalling complex. EMBO J. 20, 6347-6358.

Kimura, K., Ito, M., Amano, M., Chihara, K., Fukata, Y., Nakafuku, M., Yamamori, B., Feng, J., Nakano, T., Okawa, K. et al. (1996). Regulation of myosin phosphatase by Rho and Rho-associated kinase (Rho-kinase). Science 273, 245-248.

Klemke, R. L., Cai, S., Giannini, A. L., Gallagher, P. J., de Lanerolle, P. and Cheresh, D. A. (1997). Regulation of cell motility by mitogen-activated protein kinase. J. Cell Biol. 137, 481-492.

Kolega, J. (1998). Fluorescent analogues of myosin II for tracking the behavior of different myosin isoforms in living cells. J. Cell. Biochem. 68, 389-401.

Kolega, J. and Taylor, D. L. (1993). Gradients in the concentration and assembly of myosin II in living fibroblasts during locomotion and fiber transport. Mol. Biol. Cell 4, 819-836.

Komatsu, S. and Ikebe, M. (2004). ZIP kinase is responsible for the phosphorylation of myosin II and necessary for cell motility in mammalian fibroblasts. J. Cell Biol. 165, 243-254.

Kovacs, M., Toth, J., Hetenyi, C., Malnasi-Csizmadia, A. and Sellers, J. R. (2004). Mechanism of blebbistatin inhibition of myosin II. J. Biol. Chem. 279, 35557-35563.

Kowalczyk, A. P., Bornslaeger, E. A., Borgwardt, J. E., Palka, H. L., Dhaliwal, A. S., Corcoran, C. M., Denning, M. F. and Green, K. J. (1997). The amino-terminal domain of desmoplakin binds to plakoglobin and clusters desmosomal cadherinplakoglobin complexes. J. Cell Biol. 139, 773-784.

Kudryashov, D. S., Stepanova, O. V., Vilitkevich, E. L., Nikonenko, T. A., Nadezhdina, E. S., Shanina, N. A., Lukas, T. J., Van Eldik, L. J., Watterson, D. M. and Shirinsky, V. P. (2004). Myosin light chain kinase $(210 \mathrm{kDa})$ is a potential cytoskeleton integrator through its unique N-terminal domain. Exp. Cell Res. 298, 407417.

Lauffenburger, D. A. and Horwitz, A. F. (1996). Cell migration: a physically integrated molecular process. Cell 84, 359-369.

Leinweber, B. D., Leavis, P. C., Grabarek, Z., Wang, C. L. and Morgan, K. G. (1999). Extracellular regulated kinase (ERK) interaction with actin and the calponin homology (CH) domain of actin-binding proteins. Biochem. J. 344, 117-123.

Limouze, J., Straight, A. F., Mitchison, T. and Sellers, J. R. (2004). Specificity of blebbistatin, an inhibitor of myosin II. J. Muscle Res. Cell Motil. 25, 337-341. 
Lin, C.-H. and Forscher, P. (1995). Growth cone advance is inversely proportional to retrograde F-actin flow. Neuron 14, 763-771.

Lin, Y., Ye, L. H., Ishikawa, R., Fujita, K. and Kohama, K. (1993). Stimulatory effect of calponin on myosin ATPase activity. J. Biochem. 113, 643-645.

Lo, C. M., Buxton, D. B., Chua, G. C., Dembo, M., Adelstein, R. S. and Wang, Y. L. (2004). Nonmuscle myosin IIb is involved in the guidance of fibroblast migration. Mol. Biol. Cell 15, 982-989.

LoRusso, S. M., Rhee, D., Sanger, J. M. and Sanger, J. W. (1997). Premyofibrils in spreading adult cardiomyocytes in tissue culture: evidence for reexpression of the embryonic program for myofibrillogenesis in adult cells. Cell Motil. Cytoskeleton 37, 183-198.

Masato, T., Numata, T., Katoh, T., Morita, F. and Yazawa, M. (1997). Crosslinking of telokin to chicken gizzard smooth muscle myosin. J. Biochem. 121, 225-230.

Matsudaira, P., Jakes, R. and Walker, J. E. (1985). A gelsolin-like $\mathrm{Ca}^{2+}$-dependent actin-binding domain in villin. Nature 315, 248-250.

Matsumura, F. (2005). Regulation of myosin II during cytokinesis in higher eukaryotes. Trends Cell Biol. 15, 371-377.

McKenna, N. M., Wang, Y.-L. and Konkel, M. E. (1989). Formation and movement of myosin-containing structures in living fibroblasts. J. Cell Biol. 109, 1163-1172.

Medeiros, N. A., Burnette, D. T. and Forscher, P. (2006). Myosin II functions in actinbundle turnover in neuronal growth cones. Nat. Cell Biol. 8, 215-226.

Mitsui, T., Inagaki, M. and Ikebe, M. (1992). Purification and characterization of smooth muscle myosin-associated phosphatase from chicken gizzards. J. Biol. Chem. 267, 16727-16735.

Morgan, K. G. and Gangopadhyay, S. S. (2001). Cross-bridge regulation by thin filament-associated proteins. J. Appl. Physiol. 91, 953-962.

Murthy, K. S. (2006). Signaling for contraction and relaxation in smooth muscle of the gut. Annu. Rev. Physiol. 68, 345-374.

Nebl, T., Pestonjamasp, K. N., Leszyk, J. D., Crowley, J. L., Oh, S. W. and Luna, E. J. (2002). Proteomic analysis of a detergent-resistant membrane skeleton from neutrophil plasma membranes. J. Biol. Chem. 277, 43399-43409.

Nguyen, D. H., Catling, A. D., Webb, D. J., Sankovic, M., Walker, L. A., Somlyo, A. V., Weber, M. J. and Gonias, S. L. (1999). Myosin light chain kinase functions downstream of Ras/ERK to promote migration of urokinase-type plasminogen activator-stimulated cells in an integrin-selective manner. J. Cell Biol. 146, 149-164.

Oh, S. W., Pope, R. K., Smith, K. P., Crowley, J. L., Nebl, T., Lawrence, J. B. and Luna, E. J. (2003). Archvillin, a muscle-specific isoform of supervillin, is an early expressed component of the costameric membrane skeleton. J. Cell Sci. 116, 22612275 .

Pestonjamasp, K. N., Pope, R. K., Wulfkuhle, J. D. and Luna, E. J. (1997). Supervillin (p205): a novel membrane-associated, F-actin-binding protein in the villin/gelsolin superfamily. J. Cell Biol. 139, 1255-1269.

Poperechnaya, A., Varlamova, O., Lin, P. J., Stull, J. T. and Bresnick, A. R. (2000). Localization and activity of myosin light chain kinase isoforms during the cell cycle. J. Cell Biol. 151, 697-708.

Rhee, D., Sanger, J. M. and Sanger, J. W. (1994). The premyofibril: evidence for its role in myofibrillogenesis. Cell Motil. Cytoskeleton 28, 1-24.

Sandquist, J. C., Swenson, K. I., Demali, K. A., Burridge, K. and Means, A. R. (2006). Rho kinase differentially regulates phosphorylation of nonmuscle myosin II isoforms A and B during cell rounding and migration. J. Biol. Chem. 281, 35873-35883.

Simerly, C., Nowak, G., de Lanerolle, P. and Schatten, G. (1998). Differential expression and functions of cortical myosin IIA and IIB isotypes during meiotic maturation, fertilization, and mitosis in mouse oocytes and embryos. Mol. Biol. Cell 9, 2509-2525.

Small, J. V., Rottner, K. and Kaverina, I. (1999). Functional design in the actin cytoskeleton. Curr. Opin. Cell Biol. 11, 54-60.

Smith, L., Parizi-Robinson, M., Zhu, M. S., Zhi, G., Fukui, R., Kamm, K. E. and
Stull, J. T. (2002). Properties of long myosin light chain kinase binding to F-actin in vitro and in vivo. J. Biol. Chem. 277, 35597-35604.

Straight, A. F., Cheung, A., Limouze, J., Chen, I., Westwood, N. J., Sellers, J. R. and Mitchison, T. J. (2003). Dissecting temporal and spatial control of cytokinesis with a myosin II Inhibitor. Science 299, 1743-1747.

Stull, J. T., Lin, P. J., Krueger, J. K., Trewhella, J. and Zhi, G. (1998). Myosin light chain kinase: functional domains and structural motifs. Acta Physiol. Scand. 164, 471482.

Sumoza-Toledo, A., Gillespie, P. G., Romero-Ramirez, H., Ferreira-Ishikawa, H. C., Larson, R. E. and Santos-Argumedo, L. (2006). Differential localization of unconventional myosin I and nonmuscle myosin II during B cell spreading. Exp. Cell Res. 312, 3312-3322.

Szymanski, P. T. (2004). Calponin (CaP) as a latch-bridge protein-a new concept in regulation of contractility in smooth muscles. J. Muscle Res. Cell Motil. 25, 7-19.

Takizawa, N., Smith, T. C., Nebl, T., Crowley, J. L., Palmieri, S. J., Lifshitz, L. M., Ehrhardt, A. G., Hoffman, L. M., Beckerle, M. C. and Luna, E. J. (2006). Supervillin modulation of focal adhesions involving TRIP6/ZRP-1. J. Cell Biol. 174, 447-458.

Togo, T. and Steinhardt, R. A. (2004). Nonmuscle Myosin IIA and IIB have distinct functions in the exocytosis-dependent process of cell membrane repair. Mol. Biol. Cell 15, 688-695.

Totsukawa, G., Wu, Y., Sasaki, Y., Hartshorne, D. J., Yamakita, Y., Yamashiro, S. and Matsumura, F. (2004). Distinct roles of MLCK and ROCK in the regulation of membrane protrusions and focal adhesion dynamics during cell migration of fibroblasts. J. Cell Biol. 164, 427-439.

Ueda, K., Murata-Hori, M., Tatsuka, M. and Hosoya, H. (2002). Rho-kinase contributes to diphosphorylation of myosin II regulatory light chain in nonmuscle cells. Oncogene 21, 5852-5860.

Uehata, M., Ishizaki, T., Satoh, H., Ono, T., Kawahara, T., Morishita, T., Tamakawa, H., Yamagami, K., Inui, J., Maekawa, M. et al. (1997). Calcium sensitization of smooth muscle mediated by a Rho-associated protein kinase in hypertension. Nature 389, 990-994.

Vicente-Manzanarés, M., Zareno, J., Whitmore, L., Choi, C. K. and Horwitz, A. F. (2007). Regulation of protrusion, adhesion dynamics, and polarity by myosins IIA and IIB in migrating cells. J. Cell Biol. 176, 573-580.

Wadgaonkar, R., Nurmukhambetova, S., Zaiman, A. L. and Garcia, J. G. (2003). Mutation analysis of the non-muscle myosin light chain kinase (MLCK) deletion constructs on CV1 fibroblast contractile activity and proliferation. J. Cell. Biochem. 88, 623-634.

Wakatsuki, T., Wysolmerski, R. B. and Elson, E. L. (2003). Mechanics of cell spreading: role of myosin II. J. Cell Sci. 116, 1617-1625.

Watanabe, T., Hosoya, H. and Yonemura, S. (2007). Regulation of Myosin II dynamics by phosphorylation and dephosphorylation of its light chain in epithelial cells. Mol. Biol. Cell 18, 605-616.

Webb, D. J., Donais, K., Whitmore, L. A., Thomas, S. M., Turner, C. E., Parsons, J. T. and Horwitz, A. F. (2004). FAK-Src signalling through paxillin, ERK and MLCK regulates adhesion disassembly. Nat. Cell Biol. 6, 154-161.

Wulfkuhle, J. D., Donina, I. E., Stark, N. H., Pope, R. K., Pestonjamasp, K. N., Niswonger, M. L. and Luna, E. J. (1999). Domain analysis of supervillin, an F-actin bundling plasma membrane protein with functional nuclear localization signals. J. Cell Sci. 112, 2125-2136.

Wylie, S. R. and Chantler, P. D. (2003). Myosin IIA drives neurite retraction. Mol. Biol. Cell 14, 4654-4666.

Yang, C. X., Chen, H. Q., Chen, C., Yu, W. P., Zhang, W. C., Peng, Y. J., He, W. Q., Wei, D. M., Gao, X. and Zhu, M. S. (2006). Microfilament-binding properties of Nterminal extension of the isoform of smooth muscle long myosin light chain kinase. Cell Res. 16, 367-376. 